\title{
1 Oscillations without cortex: Working memory 2 modulates brainwaves in the endbrain of crows
}

3

4 Lukas Alexander Hahn ${ }^{1^{\star}}$, Dmitry Balakhonov ${ }^{1}$, Mikael Lundqvist $^{2}$, Andreas Nieder ${ }^{3}$ \&

5 Jonas Rose ${ }^{1,4, *}$

6

$7{ }^{1}$ Neural Basis of Learning, Institute of Cognitive Neuroscience, Faculty of Psychology, Ruhr University

8 Bochum, 44801 Bochum, Germany

$9 \quad{ }^{2}$ Department of clinical neuroscience, Psychology, Karolinska Institute, Solna, Sweden

$10{ }^{3}$ Animal Physiology, Institute of Neurobiology, University of Tübingen, 72076 Tübingen, Germany

$11{ }^{4}$ Lead contact

12 *Correspondence: lukas.hahn@ruhr-uni-bochum.de (L.A.H), jonas.rose@ruhr-uni-bochum.de (J.R.) 


\section{Relevance statement}

15 Contemporary models of higher cognition, like those of working memory, often include temporal 16 dynamics of neural activity such as gamma oscillations. Birds and mammals convergently evolved 17 these cognitive functions and here we show that, despite the large evolutionary distance and largely different brain organization, crows share many of the oscillatory fingerprints reported in primates. This indicates that neural networks required for such LFP phenomena have evolved in parallel and may be critical to higher cognition.

\section{Summary}

22 Complex cognition requires coordinated neuronal activity at the network level. In mammals, this coordination results in distinct dynamics of local field potentials (LFP) that have been central in many models of higher cognition. Because these models are based on mammalian data, they often implicitly assume a cortical organization. Higher associative regions of the brains of birds do not have cortical layering, yet these regions have neuronal single-cell correlates of higher cognition that are very similar to those found in mammals. Here we recorded LFP in the avian equivalent of prefrontal cortex while crows performed a highly controlled and cognitively demanding working memory task, adapted from monkeys. To further ensure that recordings reflected only cognitive processes detached from motor-related activities we trained and monitored the animals to keep their head still. We found signatures in local field potentials, modulated by working memory. Frequencies of a narrow gamma $(30-59 \mathrm{~Hz})$ and the beta band (13-19 Hz) contained information about the location of the target items on the screen and were modulated by working memory load. This indicates a critical involvement of these bands in ongoing cognitive processing. We also observed bursts in the beta and gamma frequencies, similar to those observed in monkeys. Such bursts are a vital part of 'activity silent' models of working memory. Thus, despite the lack of a cortical organization the avian associative pallium can create LFP signatures reminiscent of those observed in primates. This points towards a critical cognitive function of oscillatory dynamics evolved through convergence in species capable of complex cognition. 


\section{Introduction}

43 To perform the computations underlying complex cognition, the neuronal ensembles of our brains must be coordinated, otherwise, the chatter of a billion neurons may produce only noise (Lisman, 1997; Miller et al., 2018; Naud \& Sprekeler, 2018). Notably, the spiking of individual neurons follows a tight temporal organization that results in regular patterns of excitation and inhibition. At the network level, these patterns of activity can be observed in fluctuations of electrical local field potentials (LFP) that oscillate at different frequencies (Buzsáki et al., 2012, 2013; Buzsáki \& Wang, 2012). These frequencies are commonly clustered into bands, for example, the gamma band of frequencies above $30 \mathrm{~Hz}$. Gamma oscillations are likely generated in the superficial layers of cortex (Bastos et al., 2018; Buffalo et al., 2011; Maier et al., 2010), from perisomatic currents around the similarly oriented pyramidal cell layer and they arise from feedback inhibition between pyramidal cells and somatic targeting parvalbumin-positive inhibitory neurons (Buzsáki et al., 2012; Buzsáki \& Wang, 2012; Cardin et al., 2009; Carlén et al., 2012; Traub et al., 1996). Functionally, the gamma band has been suggested to be relevant for inter-regional communication of neuronal populations (Fries, 2015), and to play a key role in executive control (Miller et al., 2018). Thus, understanding these coordinated computations is the key to unlocking a functional model of higher cognition.

A cornerstone of complex cognition is working memory (WM), which enables an animal to actively retain and manipulate a limited amount of information to guide behavior (Baddeley et al., 2021). WM is also particularly well suited to investigate higher cognition from a comparative perspective. It was described almost simultaneously in humans and pigeons (Baddeley \& Hitch, 1974; Honig, 1978). Furthermore, birds and mammals show similar WM performance (Balakhonov \& Rose, 2017; Gibson et al., 2011). For example, the capacity of WM, the number of individual items that can be maintained simultaneously, is comparable between crows and macaque monkeys (Balakhonov \& Rose, 2017). Even single neuron correlates of WM in birds are virtually identical to those in mammals (Ditz \& Nieder, 2016, 2020; Moll \& Nieder, 2015; Rinnert et al., 2019; Rose $\&$ Colombo, 2005) and we recently found that this also extends to the neurophysiological limits of WM capacity (Buschman et al., 2011; Hahn et al., 2021). Given the large evolutionary distance between the species, these similarities are likely the result of convergent evolution (Emery \& Clayton, 2004; Güntürkün \& Bugnyar, 2016) and they are sharply contrasted by prominent anatomical differences. Most notably, birds lack the mammalian separation between grey and white matter along with the highly structured organization of the neocortex (Güntürkün \& Bugnyar, 2016; Harris \& Shepherd, 2015). While recent data suggest a cortex-like circuitry in sensory regions of the avian pallium, a layered neocortex-like structure is 
absent in associative avian brain regions that are crucial to WM function (Stacho et al., 2020). This includes the avian equivalent of PFC, the nidopallium caudolaterale (NCL), which shares many defining properties of the PFC, including the dense dopaminergic innervation, multimodal sensory afferents, premotor projections, and neuronal correlates for WM (Güntürkün \& Bugnyar, 2016; Herold et al., 2011; Kröner \& Güntürkün, 1999; Nieder, 2017; Waldmann \& Güntürkün, 1993).

Modern models of WM are heavily influenced by the observation of temporal dynamics in the mammalian PFC. In particular, gamma oscillations are closely associated with WM-related processes (Howard et al., 2003; Kornblith et al., 2016; Lundqvist et al., 2016; Roux et al., 2012; Tallon-Baudry et al., 1998). The highly structured organization of the layered mammalian neocortex is an ideal substrate to generate and investigate such oscillations (Einevoll et al., 2013). Consequently, models of temporal dynamics are almost exclusively built on mammalian data. However, whether these cognitive oscillations require the specific layered organization of the cortex is unclear. It has even been argued that oscillations could be an epiphenomenon of the underlying network architecture rather than a functional process in itself (Merker, 2013; Ray \& Maunsell, 2015). Therefore, the investigation of LFP in avian associative brain regions, lacking the layered organization of the cortex, offers a unique comparative perspective.

To date, only relatively few studies have investigated modulations of LFP in birds. Most prominently the optic tectum and neighboring tegmental nuclei show modulation in the gamma range during attention (Goddard et al., 2012; Neuenschwander \& Varela, 1993; Sridharan et al., 2011; Sridharan \& Knudsen, 2015). Gamma band modulations were further reported in the avian forebrain during birdsong (Brown et al., 2021; Lewandowski \& Schmidt, 2011; Spool et al., 2021), and in the avian hippocampal formation in vitro (Dheerendra et al., 2018) and during sleep (van der Meij et al., 2020). However, these observations cannot answer the question of whether oscillations underlie higher cognition since they were either made in the neatly layered optic tectum, were tightly linked to motor behavior, or occurred in sleeping birds.

Thus, descriptions of oscillatory dynamics in the non-layered endbrain of birds that are tied to abstract cognition such as WM are still lacking. Hence, it remains unknown if the single-cell similarities extend to oscillatory population dynamics that underlie higher cognition in mammals, or if birds have such cognition without oscillations. If they existed and played comparable roles in avian and mammalian WM, it would be valuable evidence towards general, cross-species mechanisms supporting higher-order cognition. 


\section{Results}

110

111

112

113

114

115

116

117

118

119

120

121

122

123

124

125

126

127

128

129

130

131

132

133

134

135

136

137

138

139

140

To investigate LFP dynamics in the avian brain during a complex form of cognition, we trained crows on a multi-item working memory task, previously used for probing WM capacity in crowns and primates (Balakhonov \& Rose, 2017; Buschman et al., 2011). On each trial, the crows were presented with a variable number of colored squares that they had to retain over a memory delay. Subsequently, the colors reappeared and the birds indicated with a single peck which of the squares now had a different color (Fig. 1A). The performance of the crows was load-dependent, gradually declining with higher loads. Median performances for item loads (ipsilateral to change) of one, two, and three were $95.88 \%, 78.31 \%$, and $58.21 \%$, respectively. This result is very similar to the performance reported in monkeys in the same task (Buschman et al., 2011), and has been discussed in detail in a previous study (Balakhonov \& Rose, 2017).

\section{LFP in the endbrain of crows is task modulated}

To investigate if WM modulates oscillations in a comparable way in crows as in primates, we analyzed LFP recorded throughout NCL from a total of 336 electrodes. We performed spectral decomposition of the recorded signal using Morlet-wavelet convolution, after removing neuronal spiking artifacts and $50 \mathrm{~Hz}$ line noise (see Methods for details). LFP power was affected throughout the time course of a trial in a frequency-dependent manner. To facilitate the comparison to results obtained in primates we subdivided frequencies into the commonly recognized LFP bands, i.e., 'theta', 'alpha', 'beta', and 'gamma' (Miller et al., 2018).

We observed modulation of LFP power in a narrow gamma frequency band $(40-52 \mathrm{~Hz})$ during the sample phase and delay phase, as well as high levels of power in a 3-8 Hz frequency band toward the end of the sample phase (Fig. 1B and C). This was also observed in the raw signal trace, most prominently in the sample and towards the end of the delay, when the individual frequency components contributed most to the composite signal (indicated by higher frequency amplitudes in Fig. 1D).

Were specific frequency bands consistently affected by the ongoing cognitive task? We tested trial averaged LFP power during the trial against stable baseline power (see Methods for details). The observations, made at the single-trial level, were consistent across trials (Fig. 2, example electrode). Power in the low band was significantly suppressed during the early sample, and at the end of the delay (Fig. 2, bottom). The high-frequency band (gamma) was significantly elevated relative to baseline during the late sample and towards the end of the delay phase (Fig. 2, top; see SFig. 1 for statistical results and further details). 


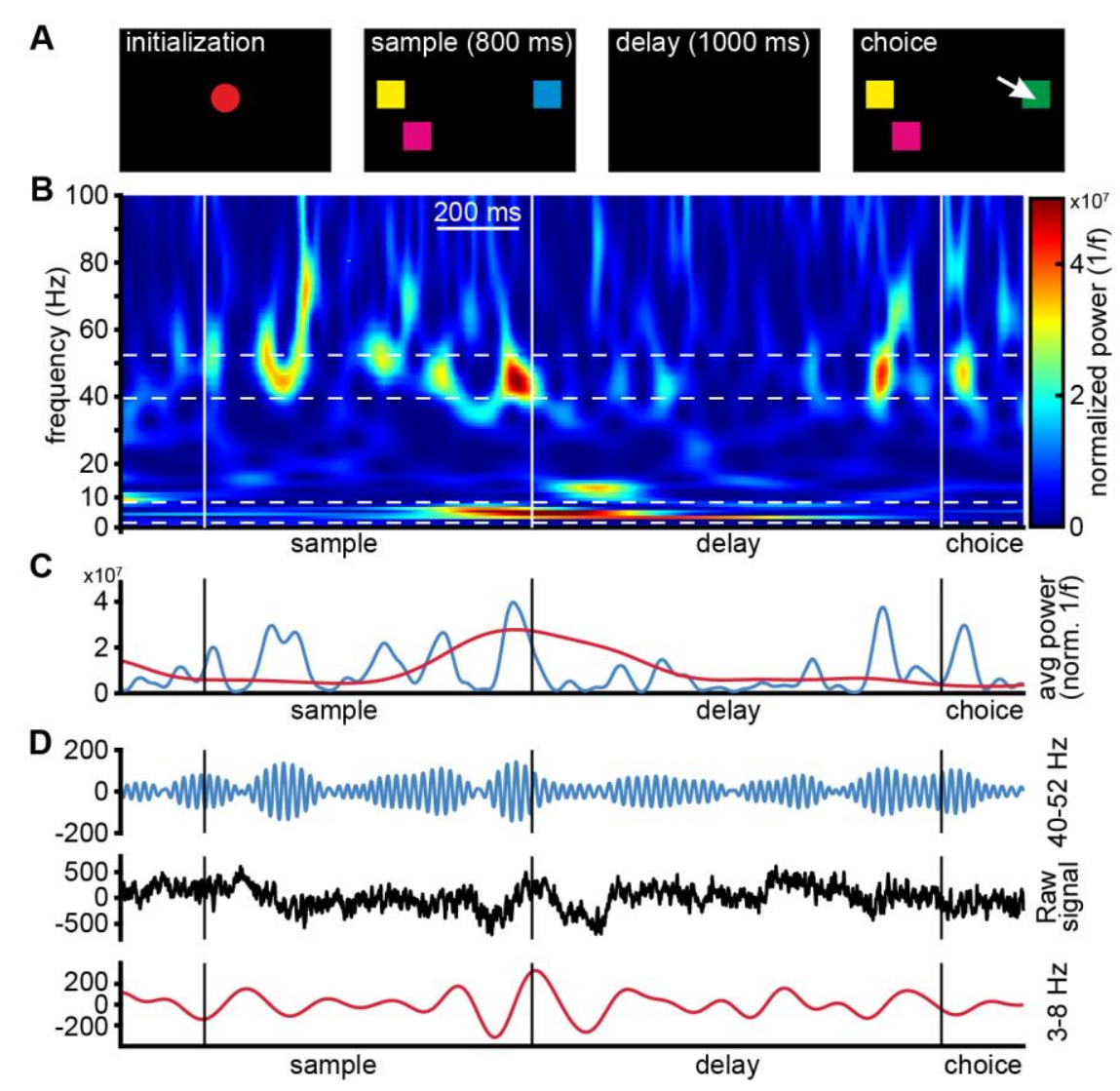

Figure 1: (A) Behavioral protocol. After the bird initiated a trial by acquiring and holding head fixation, the sample stimuli (2-5 colored squares distributed so that 0-3 colored squares appeared on each half of the screen) were presented. Birds retained head fixation and maintained color information over a memory delay, until the choice stimuli were presented (identical in color and location to those of the sample phase, except for one square that had changed color). Birds then indicated the square that changed color between sample and choice by pecking on it. (B) Single-trial example of time-frequency power of LFP. Power was elevated during the transition from sample to delay phase in a band between 3 and $8 \mathrm{~Hz}$. Higher frequencies between 40 and $52 \mathrm{~Hz}$ showed recurring increases of power in short bursts during the sample and the delay period, notably also towards the end of the delay. (C) Mean power of the selected bands across time (3-8 Hz, red, and 40-52 Hz, blue). The visible peaks correspond to the warmer colors in panel B. (D) Raw unfiltered LFP signal (black), and the same signal, band-pass filtered in the range of higher frequencies (blue), and of the lower range frequencies (red). The respective frequency components of the raw signal become visible as their amplitude increased and decreased over time.

142 This shows that modulations of LFP were generated in NCL in narrow and well-defined frequency 143 bands. These modulations reflected processing in the different task phases, and were not motor144 related, as the birds had to retain a stable head up until the choice. Because the gamma frequency 145 range was most affected by our task, we focused on electrodes that showed modulations in that 146 range. We examined the overall modulations of recorded LFP power from all electrodes with 147 significant gamma modulation (see Supplementary section 2 for more details). 

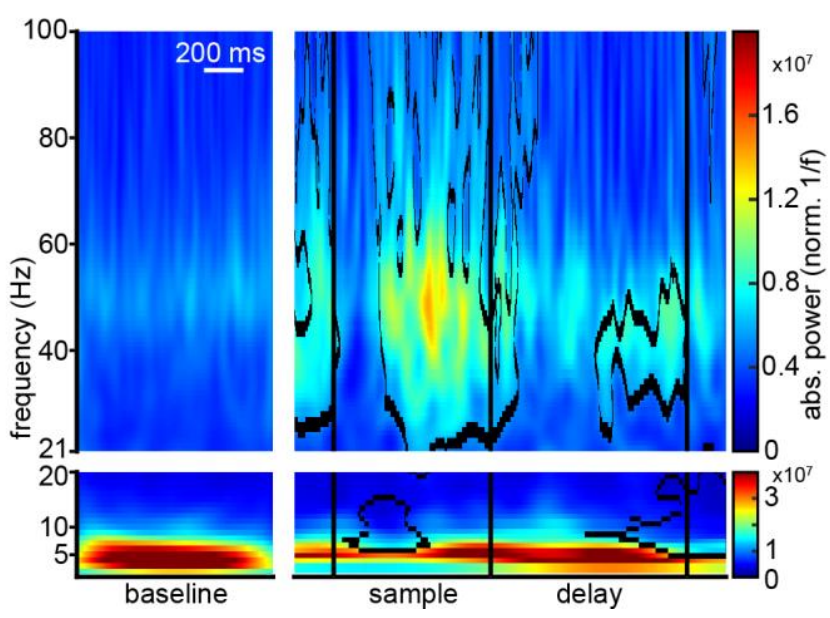

149 towards the end of the delay phase, leading up to the choice.
Figure 2: Average time-frequency power of LFP of a single electrode of a single session during the baseline period (1 second during the middle of the inter-trial-interval) and during the trial period. The duration of the pre-sample period was variable dependent on behavior, it could therefore not be used as baseline, and it contains motion and stimulus-viewing. In the sample phase an increase in gamma power, and a decrease in alpha/beta power is detectable. Outlined areas indicate power values significantly different from baseline. Higher and lower frequencies were split to highlight their respective power range that scales with $\frac{1}{f}$.

The sampled average signal showed that the task phases strongly affected the LFP. Both low gamma frequencies (33-48 Hz 'low gamma') and beta band frequencies (13-19 Hz 'beta') showed a distinct modulation by the task. The low gamma band was shortly suppressed after the sample onset, followed by an increase in power towards the end of the sample phase (Fig. 3A top). In the memory delay phase power of these frequencies remained at an elevated level (relative to baseline), and ramped up towards the end of the delay leading up to the choice. Beta frequencies initially showed strong suppression of power during the early sample phase (Fig. 3A bottom) and returned to baseline levels toward the late sample and early delay. Power was again suppressed

\section{Gamma modulation reflected working memory processing}

The described modulations in power have so far been linked to the processing of the WM task, divided into the processing of presented memory items (during sample), their maintenance (during the delay), and in anticipation of the upcoming change detection (towards the end of the delay). We investigated if our WM task caused further modulation of LFP that reflected cognitive processing of relevant stimulus dimensions, by analyzing if power of these bands contained information about the location of the presented items and if the number of items affected power. 

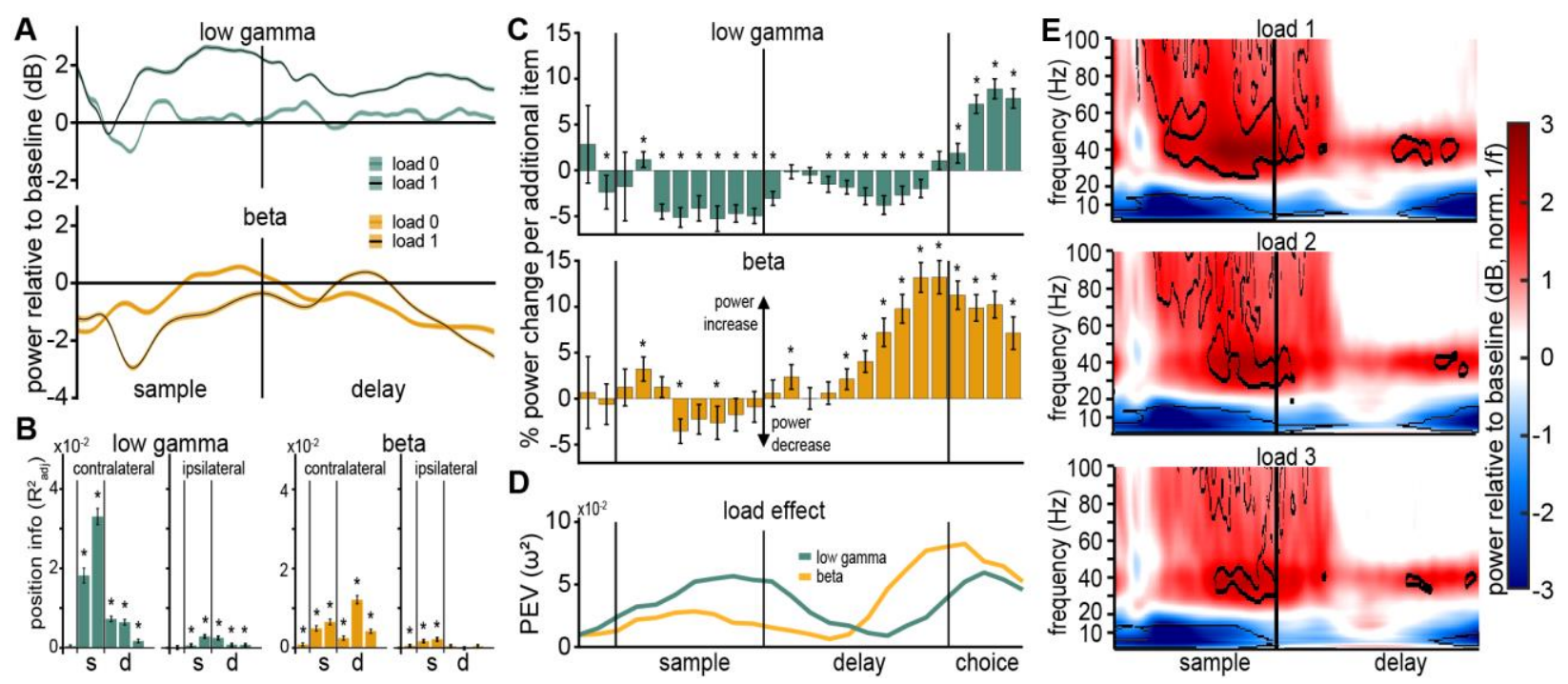

Figure 3: (A) LFP in the gamma (top) and beta (bottom) are modulated by working memory. At load 0 no stimuli were presented contralateral to the electrode, at load 1 a single contralateral stimulus was presented during the sample period. (B) Position information $\left(\Delta R_{a d j .}^{2}\right)$ contained in average power of the low gamma and beta band (400 ms bins). Power of the low gamma and of the beta frequency band contained information about the contralateral positions of stimuli, in contrast information about the positions of the ipsilateral stimuli was much smaller. Position information for low gamma frequencies was more pronounced during the sample phase than during the delay phase. Stars indicate significance at the Bonferoni corrected alpha level ( $\alpha=0.0083$; refer to SFig. 3 for other frequency bands). (C) Average change in power per added item (100 ms bins). The low gamma frequency band $(32-47 \mathrm{~Hz})$ shows a reduction of power with every added item throughout the sample delay phase, but gains power with every added item in the choice phase. The beta frequency band $(12-29 \mathrm{~Hz})$ shows a consistent increase in power with every added item throughout sample and delay phase, notably peaking towards the end of the delay. (D) Quantification of the load effect depicted in (A), as percent explained variance by factor power $\left(\omega^{2}\right)$. (E) WM load affected the time-frequency power of LFP. Average power of all electrodes with significant gamma band modulation, relative to baseline (in decibel), for load 1-3. Lower frequencies show a general suppression of power, relative to baseline, while higher frequencies show a general increase in power. The tree panels depict different WM-load (number of items contralateral to the recording electrode). Outlined areas indicate significant differences from baseline.

To estimate information about ipsilateral and contralateral positions, we applied the method of (Kornblith et al., 2016), performing model comparisons of generalized linear models (see Methods for details). For all electrodes that had significant gamma modulation (see Supplementary section

171 2), we derived position information, needed to solve the task, for the ipsilateral and contralateral

172 locations by quantifying the difference of model fits $\left(\Delta R_{a d j}^{2}\right)$, in six $400 \mathrm{~ms}$ intervals (pre-sample;

173 early/late sample; early/mid/ late delay).

174 In general, power contained information about the (task relevant) locations of presented squares

175 (Fig. 3B). This information was most prominently present during the sample phase. We found that 
of the screen (early and late sample, mean ( \pm SEM): $0.0182( \pm 0.0019), F(1,1247)=379.83, p<$ $0.0001, \omega^{2}=0.2327$ and $0.0330( \pm 0.0020), F(1,1247)=1063.8, p<0.0001, \omega^{2}=0.4597$, respectively). Beta band power contained a significant amount of information during the sample (early and late sample, mean $\left( \pm\right.$ SEM): $0.0049( \pm 0.0007), F(1,1247)=200.02, p<0.0001, \omega^{2}=$ 0.1374 and $0.0065( \pm 0.0008), F(1,1247)=299.36, p<0.0001, \omega^{2}=0.1928$, respectively $)$, and notable information during the delay (mid delay, mean ( \pm SEM), $0.0121( \pm 0.0011), F(1,1247)=$ 543.44, $\left.p<0.0001, \omega^{2}=0.2993\right)$.

Other frequency bands (3-7 Hz 'theta', 8-12 Hz 'alpha', and 83-98 Hz 'high gamma') also contained information about the contralateral position during the sample phase and delay phases (SFig. 2). However, these frequency bands had much less information compared to the low gamma band (see Supplementary section 3). None of the frequency bands had meaningful information about the ipsilateral locations (refer to the extended data table $1 \& 2$ for a detailed overview). This location information contained in LFP power indicates involvement in processing the spatial component of the task, as binding each color to a location was necessary for localizing the change detection.

\section{Working memory load modulated gamma}

The major manipulation affecting cognitive processing in our task was the number of squares the birds had to memorize as it determined the load of WM. We considered three load conditions ('loads'). Because power contained information only for contralateral locations, we analyzed load effects for the number of squares presented in the visual hemifield contralateral to the recording electrode. Trials in which only one square was presented during the sample (Fig. 1A), were considered to have 'load 1' (irrespective of the number of squares on the other side of the screen). Following this logic, trials with two, or three presented colors were considered 'load 2', and 'load 3', respectively. To understand how LFP-power was modulated by WM-load, we again compared the power of all gamma-modulated electrodes during the sample and memory delay phases to baseline power during the inter-trial interval. When comparing power across the different loads, the local maximum of power in the low gamma band appeared to be modulated, with higher loads reducing average power (Fig. 3E, SFig. 3). Similarly, the power in the lower bands appeared to be affected by load. To better quantify the load effect, we tested its effect on power in the five major frequency bands introduced above (we focus on the low gamma and the beta band that prominently affected by the overall task, refer to SFig. 4 for the other frequency bands). The mean power in the respective frequency band, across all channels with significant gamma power modulation in load 1 trials, was compared by calculating the average change in power per added 
210 item. Power in the low gamma band decreased as load increased during sample and delay but

211 reversed this modulation during the subsequent choice phase (Fig. 3C). The beta band showed

212 the opposite effect of load, with power generally increasing at higher loads. We further quantified

213 the magnitude of the load effect by calculating the effect size (PEV, $\left.\omega^{2}\right)$ of the LFP differences for

214 different loads over time (see methods for details). The influence of load on low-gamma power

215 was largest towards the end of the sample (power decreased with load), and in the choice phase

216 (power increased with load). The strongest beta power load modulation started appearing during

217 the middle of the delay phase (power increased with load), peaking at the end of the delay (Fig.

$2183 \mathrm{D}$, refer to table 3 for numerical values). This means that LFP power was substantially affected

219 by both the locations of the presented stimuli and by the WM load. Therefore, LFP processes

220 seem to be tightly linked to ongoing cognitive processing of the WM task, during both sample

221 encoding of memory items, and their subsequent maintenance during the delay.

\section{Beta and Gamma appear in bursts}

223 An additional observation we made was that power modulations in the low gamma band appeared

224 as bursts throughout sample and delay phase (Fig. 1B). In a study in which monkeys performed 225 a sequential version of our task (Lundqvist et al., 2016), increases in gamma power were found 226 to originate from sparse and temporarily defined 'bursts' of power. We tested if the increase in 227 gamma power was due to individual bursts by investigating the potential burst events (power 228 crossing a threshold of mean+1.5*SD for two cycles). We calculated burst rates over time (i.e., 229 the observed rate of bursts at any given time in a trial, see methods for details). Burst rate in the 230 low gamma band increased throughout the sample phase, peaking in the late sample phase (load 231 1, mean \pm SEM, $0.0834 \pm 0.0008$ at $620 \mathrm{~ms}$ ), before gradually reducing throughout the delay (Fig. 2324 A top, table 4, SFig. 4 for alpha and high gamma). Notably, the burst rate increased again during 233 the latest part of the delay. These burst rates were also load-dependent in two directions 234 depending on the task phase. During the sample phase, the burst rate significantly decreased 235 with load, while during the late delay phase the burst rate increased with load (Fig. 4A, refer to 236 table 5 for statistical values). The beta band also showed this effect (refer to Supplementary 237 section 4 for the other frequency bands and for a comparison of bursts to population spiking rate). 238 The phase and load-dependent rates of low gamma and beta bursts correlated with processing 239 demands of WM for encoding during the sample, maintenance during the delay, and preparation for decoding towards the end of the delay and choice phase. 
A
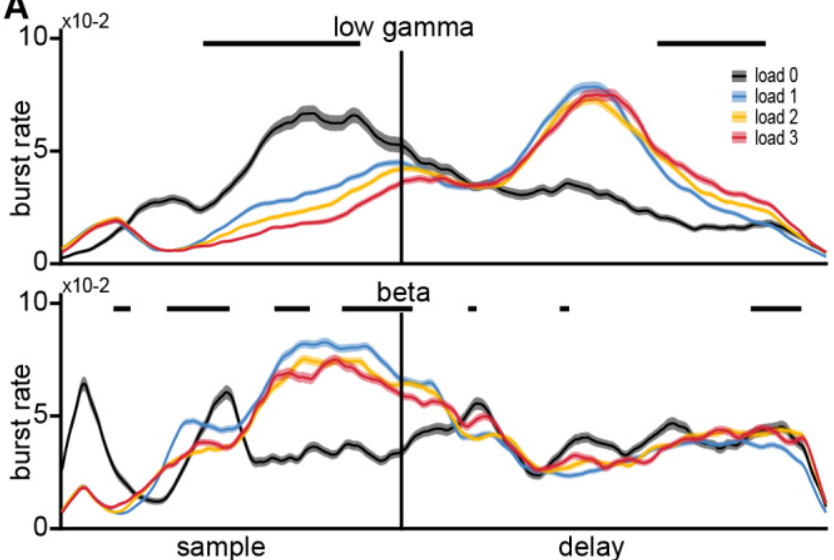

B Pyramidal inhibitory network gamma

C K winners gamma network generation

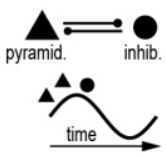

E

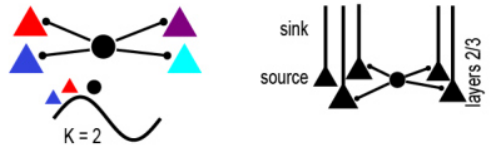

Persistent network sustained gamma
$\mathrm{K}=$ WM capacity

Synaptic/ spiking hybrid bursty gamma, $\mathrm{k}=1$

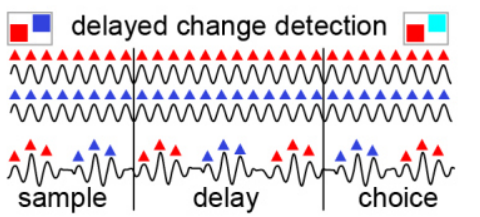

Figure 4: (A) Trial burst rate of low gamma and beta frequency bands during the trial at gamma modulated sites. Burst rate of low gamma strongly increases towards the end of the sample phase, while beta has peak burst rate in the middle of the delay. Load modulation occurs with higher loads decreasing burst rate in the sample but increasing burst rate towards the end of the delay. Black bars indicate consecutive significance between loads 1-3 $(p<0.05)$ over 2 cycles of the bands center frequency (B) Schematic generation of mammalian pyramidal inhibitory network gamma (PING). Gamma oscillation is generated in a cycle when excitatory pyramidal cells first become active, exciting inhibitory parvalbumin positive interneurons that provide dense, short-lasting feedback inhibition. The inhibition briefly shuts down the pyramidal cells to terminate the cycle. (C) Implementation of a winnertake-all dynamic. If several pyramidal populations (colored triangles) are connected to the same inhibitory population (black circle), the gamma generating feedback inhibition can implement a $\mathrm{K}$ winners take all dynamic where only the $\mathrm{K}$ most excited populations will spike before the feedback inhibition deactivates all populations. For example, the earlier spiking of blue and red in each cycle results in $\mathrm{K}=2$. (D) Cortical layer organization facilitate gamma oscillation. Many similarly aligned pyramidal cells receive rhythmic, peri-somatic inhibition. The pyramidal cells are thought to act as aligned dipoles with the source close to the somas and the sink in the apical dendrites, creating an extracellular field. The gamma in cortical LFPs is thus generated in the superficial layers of cortex. Crow NCL lacks this layered anatomical organization. (E) Two different networks solving a 2-item delay change detection task. The two colored squares can be retained either by selective, persistent activity (top) in a network where gamma implements a $\mathrm{K}=\mathrm{WM}$ capacity winner take all algorithm, or alternatively, in a network relying both on intermittent spiking and synaptic mechanisms with $\mathrm{K}=1$. In the latter, since $K=1$, the two memory representations take turn being active and silent resulting in bursting gamma. In the silent periods, information is retained in synaptic changes rather than sustained spiking. 


\section{Discussion}

243 We observed cognitively modulated oscillations of LFP in the NCL of carrion crows performing a 244 WM task. Oscillations occurred in a narrow gamma band, and in the beta band. This data shares many similarities with those observed in monkey PFC. While these results are consistent with behavioral and single-cell observations they are remarkable given that WM of birds and monkeys have diverging neuronal architectures that evolved independently over the last 320 million years (Benton \& Donoghue, 2007).

\section{Cognitively modulated non-cortical gamma}

250 The laminar and columnar organization of the mammalian cortex, with similarly aligned pyramidal cells, is thought to produce extracellular electrical fields that facilitate the observation of rhythmic population activity (Fig. 4B; (Buzsáki et al., 2012; Einevoll et al., 2013)). However, the associative pallium of birds lacks this structure entirely (Güntürkün \& Bugnyar, 2016), and the mosaic-like arrangement of fiber patches in NCL (Stacho et al., 2020) differs substantially from the highly structured, layered, organization of the PFC. Gamma oscillations in birds have first been reported in the optic tectum of pigeons (Neuenschwander \& Varela, 1993) and barn owls (Sridharan et al., 2011), a midbrain structure that like the mammalian neocortex displays a separation between grey and white matter and organization into highly structured layers (Güntürkün et al., 2020). Only recently modulated gamma was reported in the (non-layered) telencephalon of birds. In the song system of singing zebra finches (Brown et al., 2021; Lewandowski \& Schmidt, 2011), and in the hippocampus of sleeping zebra finches (van der Meij et al., 2020). Functionally involved in such gamma oscillations are excitatory cell types, homologous to mammalian excitatory neurons, which are part of neuronal circuitry that can be optogenetically induced to produce broad range gamma oscillations (Spool et al., 2021), Fig. 4B). These neurons were found in the zebra finch pallium, adjacent to NCL (Spool et al., 2021). Based on the similarities of the observations of gamma in the avian optic tectum it has been suggested that gamma rhythms play an essential role in information processing and are thus evolutionary conserved (Sridharan \& Knudsen, 2015).

We now demonstrate that the NCL of crows also shows gamma modulation of the LFP, importantly in the absence of motor planning or execution, and directly linked to cognition. This is

270 despite the anatomical differences between the layered PFC and nuclear NCL, in terms of the

271 architecture of the telencephalon at this mesoscale. Therefore, the firmly established equivalency

272 of avian NCL to mammalian PFC, both functionally (Nieder, 2017) and through its macro anatomy

273 (Güntürkün \& Bugnyar, 2016), also holds for its LFP dynamics. This expands our knowledge 
274 about how higher cognition (WM) arises in birds, i.e. following the same oscillatory dynamics

275 observed in mammals.

\section{Gamma modulation related to WM}

277 Remarkably, the telencephalic LFP power dynamics in the gamma frequency range is observed across species in a similar fashion: it was elevated during stimulus encoding, contained information about stimulus location, reduced during the early delay, and ramping up towards the end of the delay (Kornblith et al., 2016; Lundqvist et al., 2016).

The observation that gamma oscillations have similar cognitive correlates in crows as in mammals, despite key anatomical differences, could point towards a key functional advantage of rhythmic population activity. This argument was previously made based on the conserved temporal properties across vastly different mammalian brain sizes (Buzsáki et al., 2013). Cortical gamma is thought to implement a winner-take-all algorithm (Fig. 4C) that simultaneously promotes selective neuronal activity without runaway excitation due to divisive normalization (Fries, 2015; Lundqvist et al., 2010). Together with analysis from single-neuron activity in crows (Hahn et al., 2021), it suggests that crow gamma could have a similar role in selection and normalization despite being implemented on a different neural substrate.

290 We also report that avian gamma is 'bursty' rather than a continuous and prolonged increase in 291 power. The smooth elevation during stimulus encoding and the smooth increase during the end 292 of the delay was visible only in the trial averages, at the single-trial level it was only elevated 293 above baseline in brief bursts. Such bursts of gamma have also been observed in human and 294 non-human primate cortex (Kucewicz et al., 2017; Lundqvist et al., 2016; Lundqvist, Herman, 295 Warden, et al., 2018). They provide support for models in which WM information is retained by a 296 combination of spiking and synaptic mechanisms (Fig. 4E; (Lundqvist et al., 2011; Mongillo et al., 2008; Sandberg et al., 2003)). The role of the bursts may be to facilitate reliable synaptic transmission (Lisman, 1997) and to leave a plastic synaptic mark of WM at the synapse (Miller et al., 2018). This, and other related findings, have motivated models of WM in which retention can be achieved by 'activity silent' mechanisms, i.e., synaptic plasticity following bursts of spiking (Lundqvist, Herman, \& Miller, 2018; Miller et al., 2018; Sreenivasan \& D’Esposito, 2019). However, there is an ongoing debate over these models and the more classical model of WM retention through observable sustained spiking (Constantinidis et al., 2018; Wang, 2021). 
networks, alpha/beta oscillations are thought to play an inhibitory role and suppress gamma and the associated processing of sensory information (Händel et al., 2011; Jensen \& Mazaheri, 2010; Lundqvist et al., 2016). Gamma band activity, in contrast, is associated with active encoding and decoding of WM information, e.g., when information has to enter WM, or when it is retrieved (Lundqvist et al., 2016; Roux et al., 2012; Sederberg et al., 2003). Thus, during these gamma active phases, the neuronal networks are plastic. Alpha/beta band activity is associated with retention (e.g., during the delay) that safeguards encoded information against perturbation. Our data are largely in line with these ideas, although we also observed some deviations from such mammalian data and model-predictions as outlined above.

\section{Deviations from mammalian models}

Despite these striking similarities in the overall modulation of oscillatory activity by task epochs between birds and mammals, we also observed key deviations, in particular for load-dependent effects: despite gamma increasing during WM-encoding (load 1 vs load 0), it subsequently decreased with load. This is in stark contrast to studies from human and non-human primates in which gamma increases monotonically with load (Howard et al., 2003; Kornblith et al., 2016; Lundqvist et al., 2016; Meltzer et al., 2008; Roux et al., 2012).

From a modeling perspective, this pattern could potentially be explained by an increase of simultaneously active populations as load increases. Each population codes for distinct items. Due to the lack of columnar alignment, they could potentially cancel out each other's contribution to the measured field when more than one is active (in contrast to the cortical alignment, Fig. 4D). However, the positive correlation between load and gamma at the end of the delay and in the choice period could speak against an anatomical explanation for this cross-species discrepancy. It should also be noted that single-neuron spiking only showed a load-dependent effect towards the end of the delay (where it increased with load, similar to mammals), suggesting there are cross-species differences in the population activity, particularly at encoding and not only in the measured LFP. This poses a challenge to existing models of working memory that tend to assume increased cognitive load is supported by increased (or at least not decreasing) population activity (Lundqvist et al., 2011). Another possible explanation could be that the birds processed the memory items differently during the sample and at the end of the delay. Because memory items were presented simultaneously, the birds might have processed them as one during the sample, but then shifted to an individual representation during the delay, like cycling through the individual colors one by one. Task-dependent changes, depending on the behavioral relevance, in the neural representations of WM items, have been reported in monkeys (Panichello \& Buschman, 

2021). If there's a difference between those modes, it might explain why our observations are congruent with those of monkeys from a full sequential version of the task only at the end of the delay (Lundqvist et al., 2016).

We cannot exclude the possibility that some methodological differences (in comparison to monkeys) could have caused our observed deviations. We trained our birds to retain head fixation without restraining them which might have caused effort-related signals that attenuated some effects. Similarly, we did not explicitly control for eye movements. Importantly though, these differences were necessary to attain recordings that would allow our novel LFP analysis of purely task-related cognition. Motor-related activity in particular would have hindered such isolated analysis. Overall, the complex pattern with different load effects during encoding and choice, and non-monotonic changes from load 0 to load 3, points towards intriguing differences in the evolved implementations between mammals and birds. In addition, while gamma and alpha/beta tended to be elevated and suppressed in different parts of the trials, this relationship did not seem as strong as that in primates. For instance, the load effects for gamma and beta bursts went in the same, not opposite, directions as one would expect if they were anti-correlated.

The fact that birds have similar WM capacity, and striking similarities in the neural WM activity, makes these differences more relevant as clues towards what dynamical features are vital to support higher order cognition. Future modelling and avian neurophysiological studies hold significant promise to reveal such principles.

\section{Methods}

Our animals, experimental setup, behavioral protocol, recording setup, and surgical procedures were previously described in (Hahn et al., 2021).

\section{Subjects}

We worked with two hand-raised carrion crows (Corvus corone), held under identical housing and food protocols as described in (Hahn et al., 2021). All experimental procedures and housing conditions were carried out in accordance with the National Institutes of Health Guide for Care and Use of Laboratory Animals and were authorized by the national authority (LANUV).

\section{Experimental setup}

Our setup consisted of an operant training chamber outfitted with a touchscreen (22", ELO 2200 L APR, Elo Touch Solutions Inc., CA) and an automatic feeder delivering food reward upon correct pecks on the touchscreen. We used two computer vision cameras ('Pixy', CMUcam5, Charmed Labs, Tx) to track the birds' head position via a mount of two lightweight 3D-printed LEDs that 
was removed after each experimental session. Head-location was acquired at $50 \mathrm{~Hz}$ and data was smoothed by integrating over 2 frames in Matlab using custom programs on a control PC. The behavioral paradigm was executed by custom code written in Matlab using the Psychophysics (Brainard, 1997) and Biopsychology toolboxes (Rose et al., 2008). Further details about the experimental setup have been reported in (Hahn et al., 2021).

\section{Behavioral protocol}

We trained the birds to perform a delayed non-match to sample task, previously used to test the performance under different working memory loads in primates (Buschman et al., 2011). The protocol has previously been reported by Hahn et al., (2021). Trials started with the presentation of a red dot centered on the touchscreen (for a maximum of $40 \mathrm{~s}$ ). Centering of the head in front of the red dot for $160 \mathrm{~ms}$ caused the red dot to disappear and a stimulus array of two to five colored squares to appear (Fig. 1A, 'sample'). The sample was presented for $800 \mathrm{~ms}$, while the animals had to maintain head fixation and center their gaze on the screen ('hold gaze', no more than $2 \mathrm{~cm}$ horizontal or vertical displacement, and no more than $20^{\circ}$ horizontal or vertical rotation). Failure to retain head fixation resulted in an aborted trial. The sample phase was followed by a memory delay of $1000 \mathrm{~ms}$ after which the stimulus array reappeared with one color exchanged. The animal indicated which of the colors had changed by pecking the respective square. Correct responses were rewarded probabilistically (BEO special pellets, in $55 \%$ of correct trials, additional 2 s illumination of the food receptacle in $100 \%$ of correct trials). Incorrect responses to colors that had not changed or a failure to respond within $4 \mathrm{~s}$ resulted in a brief screen flash and a $10 \mathrm{~s}$ timeout. Individual trials were separated by a $2 \mathrm{~s}$ inter-trial interval.

The colored squares were presented at six fixed locations on the screen (1 - 6, Fig. 1A). In each session, one pair of colors was assigned to each of the six locations. Each location had its own distinct pair. These pairs were randomly chosen from a pool of 14 colors (two color combinations were excluded since the animals did not discriminate them equally well during a pre-training). Fig. $1 \mathrm{~A}$ gives an example. The color-change occurs for the middle right where blue $(\mathrm{B})$ is presented during the sample and green $(\mathrm{G})$ during the choice. In this particular session, the middle-right location could thus show either of the following colors during the sample and choice: $B-G$ (shown in Fig. 1A); G-B; G-G; B-B; None-None. On the next session, a new random pair of colors were displayed at this location. The order of presentation of colors within a pair, the target location (where the color change occurred), and the number of stimuli in the array (two to five) were randomized and balanced across trials so that each condition had an equal likelihood to appear. The width of the colored squares was 10 degrees of visual angle (DVA) and squares were placed 
on the horizontal meridian of the screen and at 45.8 DVA above or below the meridian at a distance of 54 and 55.4 DVA from the center. The binocular visual field of crows is 37.6 DVA (Troscianko et al., 2012). With our arrangement on screen, combined with the head tracking, we ensured that all stimuli appeared only outside of this binocular range.

\section{Surgery}

The surgery protocol was identical to the one reported by Hahn et al., (2021). Both animals were chronically implanted with a lightweight head-post to attach a small LED holder during the experiments. Before surgery, animals were deeply anesthetized with ketamine $(50 \mathrm{mg} / \mathrm{kg})$ and xylazine $(5 \mathrm{mg} / \mathrm{kg})$. Once deeply anesthetized, animals were placed in a stereotaxic frame. After attaching the small head-post with dental acrylic, a microdrive with a multi-channel microelectrode was stereotactically implanted at the craniotomy (Neuronexus Technologies Inc., Ann Arbor MI, DDrive). The electrode was positioned in NCL (AP 5.0, ML 13.0) of the left hemisphere (coordinates for the region based on histological studies on the localization of NCL in crows (Veit \& Nieder, 2013). After the surgery, the crows received analgesics.

\section{Electrophysiological recordings of single-cell activity and LFP}

Recordings of neuronal activity (local field potentials and single-cell spiking) were performed using chronically implanted multi-channel microelectrodes. The distance between individual recording sites (electrodes) was $50 \mu \mathrm{m}$. The signal was amplified, filtered, and digitized using Intan RHD2000 headstages and a USB-Interface board (Intan Technologies LLC, Los Angeles CA). The system also recorded digital event codes that were sent from the behavioral control PC using a custom IO-device (details available at www.jonasrose.net). Before each recording session, the electrodes were advanced manually using the microdrive. Recordings were started 20 minutes after the advancement, and each recording site was manually checked for neuronal signals (cellular discharges observable on an audio monitor). Signals of analysis of LFP were recorded at a sampling rate of $30 \mathrm{kHz}$ and filtered with a band-pass filter at recording (1 Hz - 7.5 kHz). LFP signals were then further processed by offline down-sampling to $1 \mathrm{kHz}$. For analysis, we chose to systematically sub-sample a quarter of all electrodes used (i.e., analyzing signals from every fourth electrode, thereby achieving a reduced overlap of signal with $200 \mu \mathrm{m}$ distance between electrodes). To verify our results we applied analysis to a second, independent subsample of the electrodes. Qualitative results from this second subsample were comparable. Data of single-cell neuronal activity for analysis of the spiking rate of the neuronal population (SFig. 5), was obtained from our previous study (Hahn et al., 2021). 


\section{Processing of LFP results}

438 Prior to extracting frequency power from our signals, we removed possible spike-related traces from the LFP signals using the algorithm of (Banaie Boroujeni et al., 2020). We further processed our LFP signals using the FieldTrip open-source software package for Matlab (Oostenveld et al., 2010). We extracted frequency power from the signals using Morlet-wavelet convolution with a Morlet family of 99 frequencies $(2-100 \mathrm{~Hz})$, with seven wavelet cycles. We screened all trials for unique trial artifacts centered around $50 \mathrm{~Hz}$ during processing. On rare occasions electrodes had

444 individual trials that showed magnitudes of frequency power up to three magnitudes of power

445 larger than the next biggest power value, we handled such artifacts by restricting data analysis to 446 the $99^{\text {th }}$ percentile of power values on any electrode (i.e., excluding trials from analysis whose power values fell into the top $1 \%$ of observed values). During manual curation of results we nonetheless observed a few electrodes with power levels exceeding their average levels at distinct time points over all frequencies (i.e. power surges not restricted to any specific frequency). Those electrodes $(n=31)$ were subsequently removed from data analysis altogether.

\section{Statistical testing of power during the trial against baseline power}

452 We tested frequency power during the trial (in load conditions 1-3, at a $1 \mathrm{~ms}$ time resolution, 453 across all individual frequencies) against baseline frequency power using a dependent samples 454 t-statistic (i.e., testing the trial phase for a specific load against its baseline during the preceding $455 \mathrm{ITI})$ using a permutation approach implemented in the FieldTrip toolbox. The method compares 456 the observed t-statistic of the data (i.e., trial vs. baseline) to a null-distribution t-statistic of the 457 permutated dataset. We used 1000 permutations, an alpha level of $5 \%$ to determine significance, 458 and an extreme distribution of statistical values to correct for multiple comparisons (i.e., correction 459 was achieved by comparing observed statistical values against the most extreme (minimal and 460 maximal) permutated values).

\section{Calculating gamma modulation of individual electrodes}

462 We determined if an electrode was 'gamma modulated' by performing the statistical testing 463 described above for the average power of the 'low gamma band' (30-59 Hz) at load 1, in $100 \mathrm{~ms}$ 464 bins with $100 \mathrm{~ms}$ steps for the interval beginning at sample start until delay end. We classified electrodes as gamma modulated if two consecutive, non-overlapping bins had been classified as significant.

\section{Statistical testing of power at different loads}

468 We tested the average change in power per added item in five frequency bands (3-7 Hz 'theta', 469 8-12 Hz 'alpha', 13-19 Hz 'beta', 30-59 Hz 'low gamma', and 83-98 Hz 'high gamma') in bins of 
100 ms with a step size of 100 ms. To do so we first calculated the average power within each frequency band and bin then normalized the average power of each electrode relative to its load 1 condition (i.e., so that power at load 1 was 1 and powers at load 2 and 3 were relative to that), and finally calculated the average between the differences of load1 and load 2, and load 2 and load 3 (Eq. 1).

Equation 1: Power $\Delta_{\text {item }}=\frac{\Delta_{\text {load } 1, \text { load } 2}+\Delta_{\text {load } 2 \text { load } 3}}{2}$

We tested if $P$ ower $\Delta_{\text {item }}$ was significant by performing a t-test of each individual value against the null-hypothesis that it was non-different from 0 , and corrected for multiple comparisons using the Bonferoni method (i.e., $\alpha_{\text {crit. }}=0.0013$ ). We calculated the effect size of the load effect quantified by Power $\Delta_{\text {item }}$ by performing a repeated measures ANOVA (measurements for each electrode at loads 1-3 respectively) over all electrodes and calculating the effect size $\left(\omega^{2}\right)$ for all individual bins (Eq. 2).

$$
\text { Equation 2: } \omega^{2}=\frac{S S_{\text {effect }}-\left(d f_{\text {load }} * M S_{\text {error }}\right)}{S S_{\text {total }}+M S_{\text {error }}}
$$

\section{Model comparison for location information}

To investigate if LFP power contained information about the location of presented stimuli we performed a comparison of generalized linear models (GLM) applying the method of (Kornblith et al., 2016), for comparability of results. We compared a 'full model', containing nested load and location information, to two 'reduced models' where we removed location information about the ipsilateral, or contralateral locations, and replaced the respective position indicators with their sum. Each model was calculated assuming a normal distribution and its canonical 'identity' link function $(f(\mu)=\mu)$. For comparison, we also assumed a gamma distribution together with its canonical link function $\left(f(\mu)=\frac{1}{\mu}\right)$. Results of both approaches were similar, but model parameters indicated that the assumption of gamma distribution did not fit all electrodes' data, whereas the normal assumption did. We, therefore, decided to report the results of the normal models. The full model was a GLM with frequency-band power as response variable and the six possible locations as predictors. Each of the six predictors was therefore encoded as either 0 (no color at the location) or 1 (color at the location). For the reduced model we replaced three of the location indicators (either those for the contralateral locations 4-6 or those for the ipsilateral locations 13), by their cumulative load (i.e., 0 - 3). The reduced models thereby lacked information about the respective locations, which, if they were informative about the LFP power, would reduce the model fit (quantified by $R_{a d j .}^{2}$ ). The difference between the model fits (i.e., $\Delta R_{a d j \text {.) }}^{2}$ then indicates how 
501 much information was contained by the respective sides locations. We calculated this model

502 comparison for six 400 ms bins, with a step size of $400 \mathrm{~ms}$, starting $400 \mathrm{~ms}$ before sample onset

503 and ending $200 \mathrm{~ms}$ after choice onset. We calculated if $\Delta R_{a d j}^{2}$. was significant in a particular bin

504 by comparing $\Delta R_{a d j \text {. }}^{2}$ to a null-distribution $\Delta R_{a d j . N u l l}^{2}$ generated from the data by permutation of the

505 data labels prior to performing the model comparison 1000 times. $\Delta R_{a d j}^{2}$. was considered 506 significant if it was bigger than $99.17 \%$ of permutated $\Delta R_{a d j . N u l l}^{2}$ values (i.e., at an alpha level of $5075 \%$, after Bonferoni correction for multiple comparisons).

\section{Calculating burst rates}

509 Burst rates of the individual frequency bands were calculated by detecting threshold crossings of 510 power. Frequency-band power qualifying as burst activity was defined as a power crossing a 511 threshold of mean $+1.5^{\star} \mathrm{SD}$, for at least two consecutive cycles (periods) of the bands center 512 frequency. For example: to classify an increase in power as a burst in the low gamma band, power 513 had to exceed threshold levels for $3 * \frac{1}{\text { centerfrequency }}=3 * \frac{1}{45 \mathrm{~Hz}}=66 \mathrm{~ms}$. We performed this 514 analysis with a sliding window starting at the start of the sample phase and ending with the end 515 of the delay. 


\section{5}

526

527

528

529

530

531

532

533

534

535

\section{Supplementary Material}

\section{Supplementary section 1}

Low frequencies in Fig. 2. Local minimum during the early sample phase occurred for a band between 8 and $20 \mathrm{~Hz}$ : avg. Local minimum at $8 \mathrm{~Hz}, 238 \mathrm{~ms}$ : $\left.3.1780^{*} 10^{6} \pm 3.4119^{*} 10^{5}\right)$. The frequency band between 4 and $20 \mathrm{~Hz}$ had minimal power at the end of the delay (avg. local minimum within significant region at $16 \mathrm{~Hz}, 1723 \mathrm{~ms}$ : $\left.2.6861 \times 10^{\wedge} 6 \pm 3.6926^{\star} 10^{\wedge} 5\right)$.

High frequencies in Fig. 2. Power peaks of the higher frequencies were clustered in a band centered around $47 \mathrm{~Hz}$ during the middle of the sample phase (avg. local maximum of the sample phase ( \pm standard error of the mean (SEM)) within significant region at $47 \mathrm{~Hz}, 483 \mathrm{~ms}: 1.4211^{*} 10^{7}$ $\pm 2.0555^{\star} 10^{6}$ ) and several smaller power peaks occurred throughout the delay phase (Fig. 2).

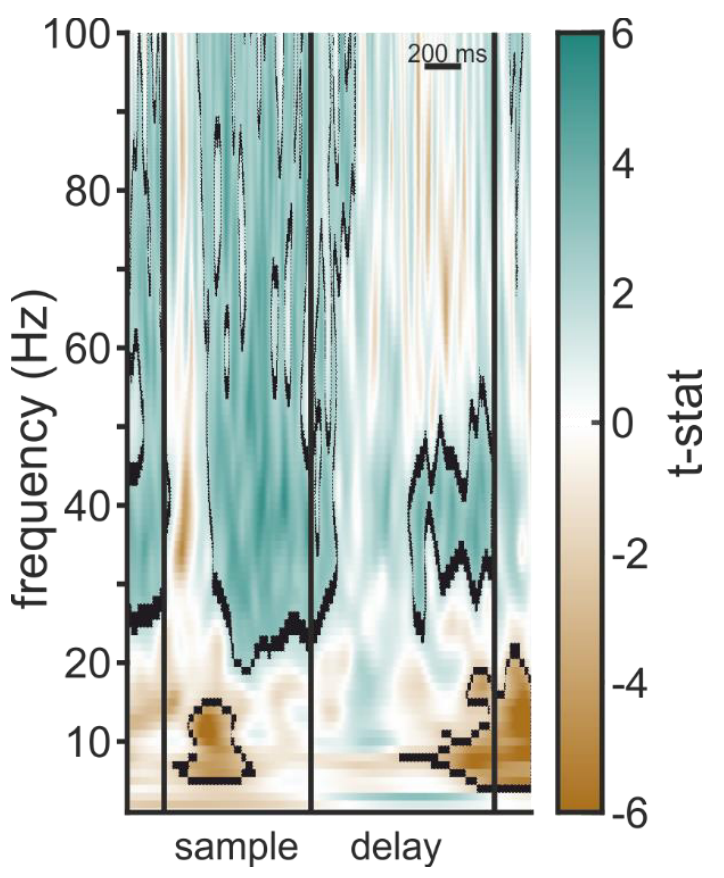

SFigure 1: Statistical values of example electrode (Fig. 2). T-values of the significance test of load 1 vs. baseline, axes are identical to those in Fig. 2. Positive values (green) indicate that power was larger than baseline, negative values (brown) indicate that power was smaller than baseline. 


\section{Supplementary section 2}

544 Gamma power modulation throughout NCL: The peaks in power in the high gamma frequency

545 bands were the most prominent observation at the level of individual electrodes. Was this a 546 general effect throughout the extent of NCL or was it localized only at specific electrodes, as has 547 been observed in monkey PFC (Lundqvist et al., 2016)? We determined if our electrodes could 548 be classified into 'gamma-modulated' and 'non-modulated' sites, by calculating significance of a 549 low $(32-47 \mathrm{~Hz})$ and high gamma $(60-100 \mathrm{~Hz})$ band during the sample phase for each of our 550 electrodes (see methods for details). We found that power in the low gamma band was 551 significantly modulated at $81.64 \%$ of electrodes (76.72 \% for high gamma). The electrodes 552 without significant gamma modulation came from recordings obtained at locations within 553 individual sessions (i.e., sessions in which there was no gamma modulation detected at any site), 554 i.e., gamma modulation was either present or absent at the sites of any given recording session.

555 Interestingly, due to the direction of the load effect (i.e., decreasing and increasing power of the 556 high and low-frequency bands, respectively) higher loads seemed to push power levels closer to 557 baseline levels for both frequency bands, while an overall activation (gamma bands), or 558 suppression (theta to beta bands) of power was present (Fig. 3A, C \& E).

\section{Supplementary section 3}

Power modulation based on the location of stimuli: Power of LFP contained information about the location of the colored square, mainly about the contralateral locations, but not for the ipsilateral locations. The absolute amount of information contained in LFP power in our data seemed to be slightly higher than that observed in monkeys (Kornblith et al., 2016). Position information was only present during the sample phase, not during the delay, and only for the positions contralateral to the electrode site, this indicates that gamma power plays a part in processing stimulus location unihemispherically. The optic nerve of birds is fully decussated, i.e.

567 information observed by the right eye ends up (via the major visual pathway) exclusively in the 568 left hemisphere (Husband \& Shimizu, 2001). We designed our task to make use of this 569 neuroanatomical isolation. Birds had to retain head fixation so that stimuli of the right side of the 570 screen (the side contralateral to electrode implantation) were only visible to the right eye. Our 571 results seem to reflect this manipulation indicating that interhemispheric 'cross talk' did not happen 572 during WM encoding in the sample phase, suggesting independent hemispheric processing. This 573 is in line with results from monkeys (Brincat et al., 2021; Buschman et al., 2011; Kornblith et al., 5742016 ) and the behavioral results of this study (Balakhonov and Rose, 2017). 

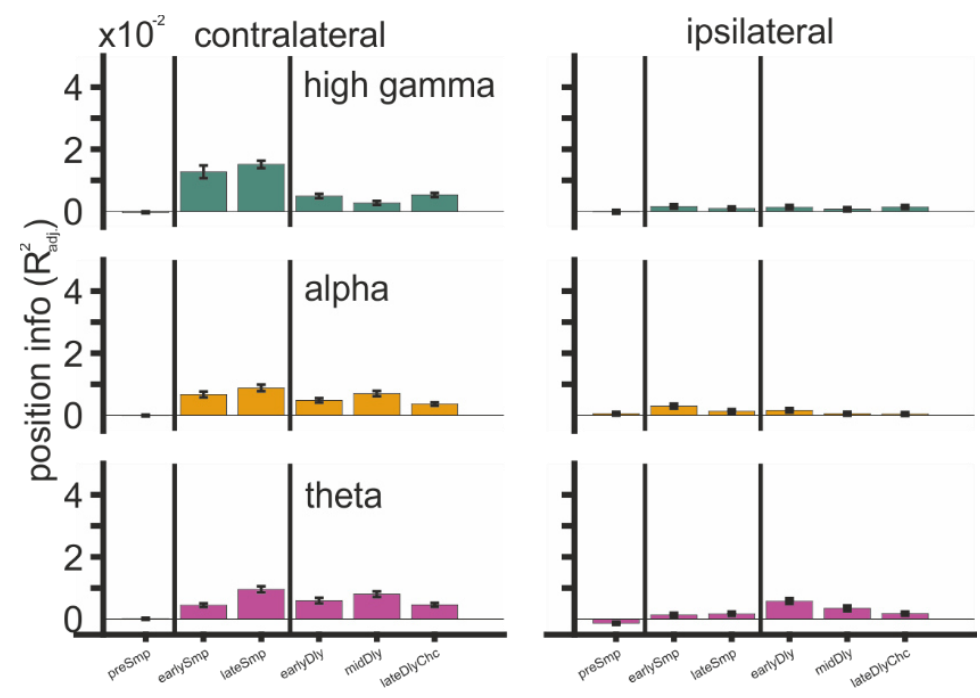

577 SFigure 2: Position information $\left(\Delta R_{a d j}^{2}\right.$. $)$ contained in average power of the theta, alpha, and high gamma bands (400 ms bins).
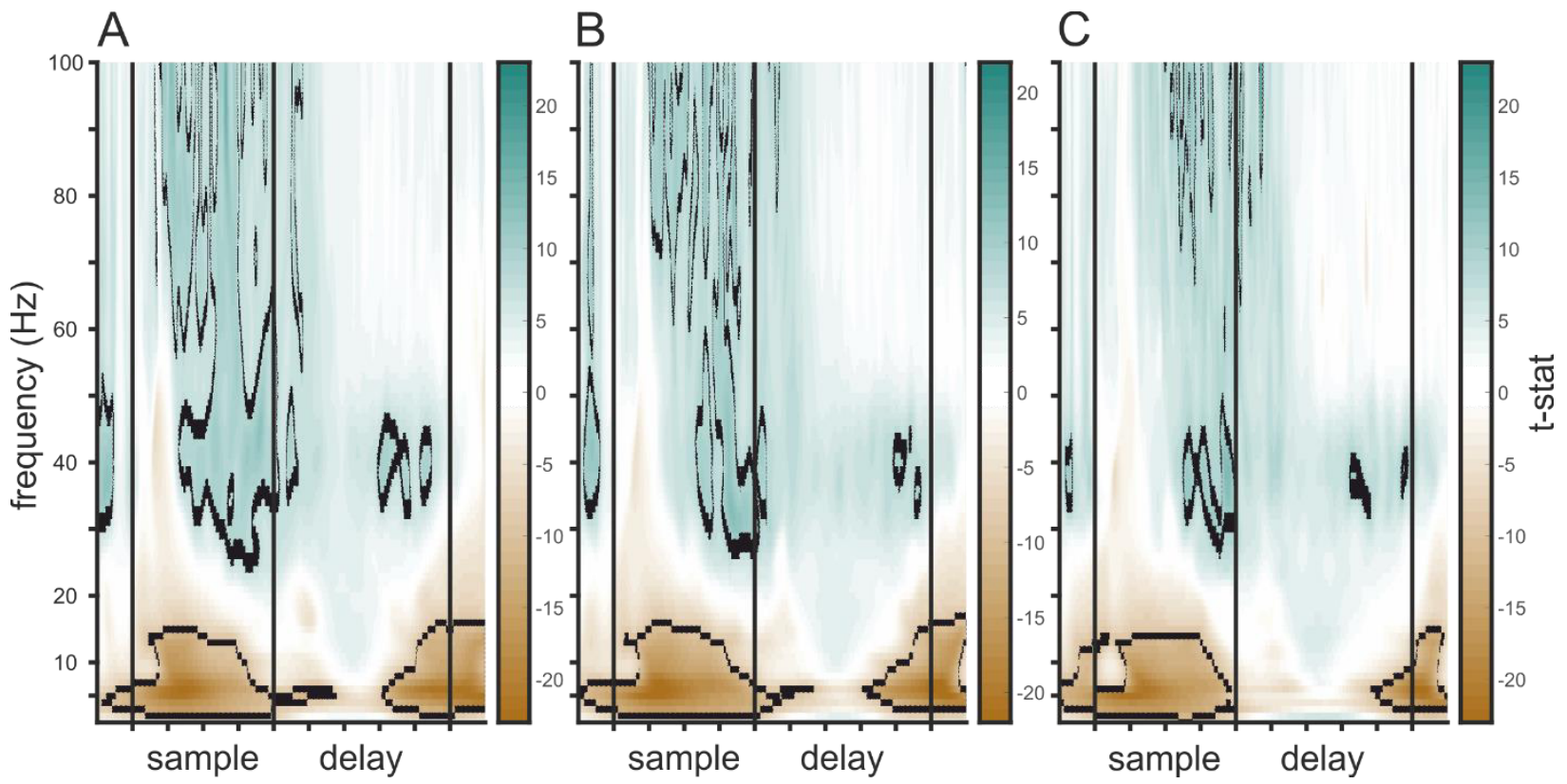

SFigure 3: Statistical values of all significant electrodes, axes are identical to those in Fig. 3E. (A) T-values of the significance test of load 1 vs. baseline. (B) T-values of the significance test of load 2 vs. baseline. (C), T-values of the significance test of load 3 vs. baseline. 


\section{Supplementary section 4}

586

587

588

589

590

591

592

593

594

595

596

597

598

599

600

601

Bursts were also present in the alpha and high gamma frequency bands, where bursts occurred during early sample, reducing with load and remaining load-independent at a stable level during late sample, before gradually reducing throughout the delay (SFig. 4, table 4 \& 5).
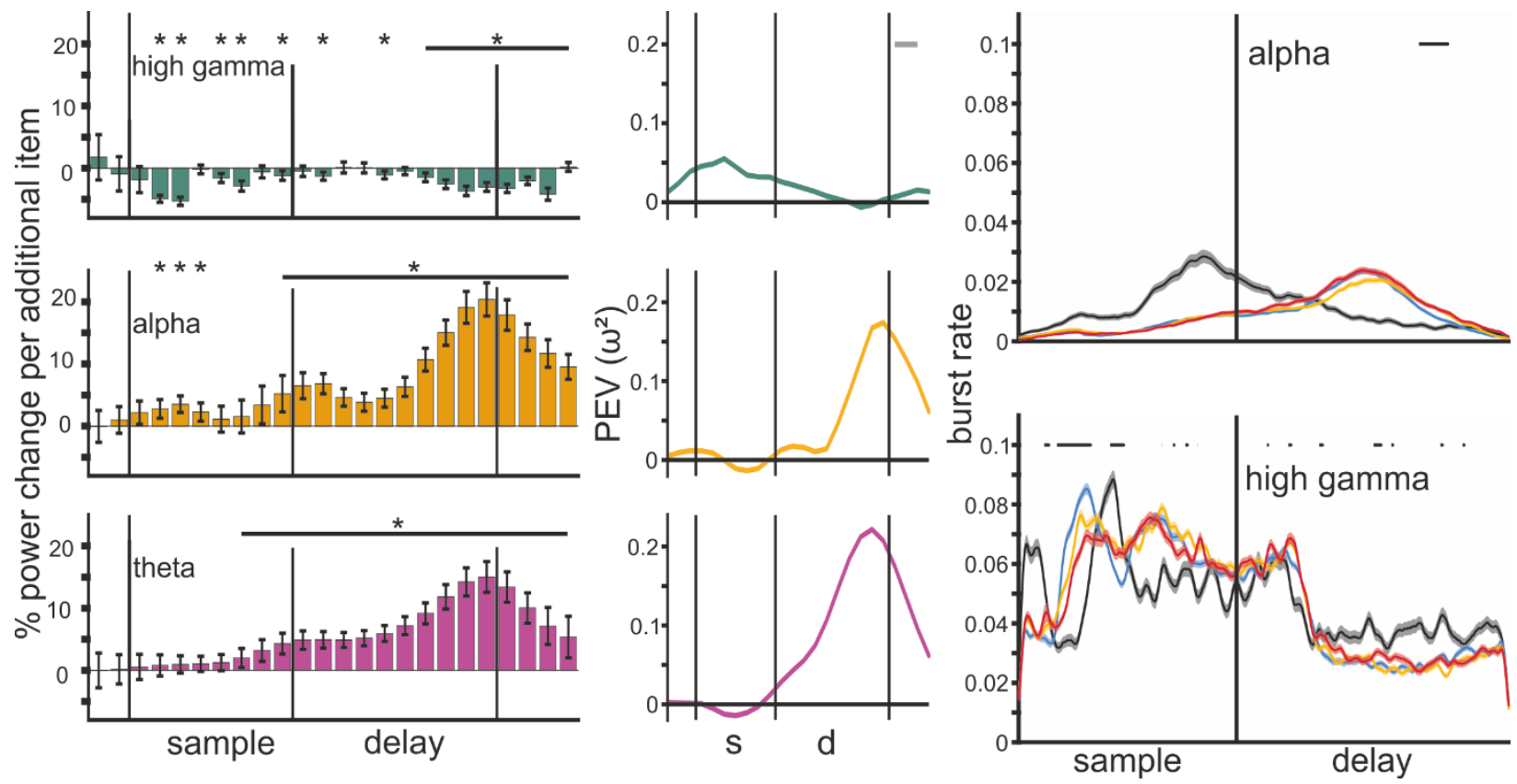

SFigure 4: Left column: Average change in power per added item (100 ms bins) for the theta, alpha, and high gamma band. Middle: Quantification of the load effect depicted in the left column, as percent explained variance by factor power $\left(\omega^{2}\right)$. Right column: Trial burst rate of alpha and high gamma frequency bands during the trial at gamma modulated sites. Black bars indicate consecutive significance between loads 1-3 $(p<0.05)$ over 2 cycles of the bands center frequency.

Neuronal spiking of the population. We also compared the load effect of bursts to the spiking activity of the neurons recorded at the same time. The population of neurons increased its spiking rate during the early sample period and then gradually reduced it throughout the rest of the trial until the choice phase (SFig. 5). Load only significantly affected spiking rate towards the end of the delay, with higher loads slightly increasing spiking rate $\left(F(1,2)=1.3, p=0.001, \omega^{2}=0.01\right.$, posthoc comparisons between load $1 / 2$ and load $2 / 3$, both $p<0.05$ ). 
bioRxiv preprint doi: https://doi.org/10.1101/2022.02.01.478165; this version posted February 2, 2022. The copyright holder for this preprint (which was not certified by peer review) is the author/funder, who has granted bioRxiv a license to display the preprint in perpetuity. It is made available under aCC-BY 4.0 International license.

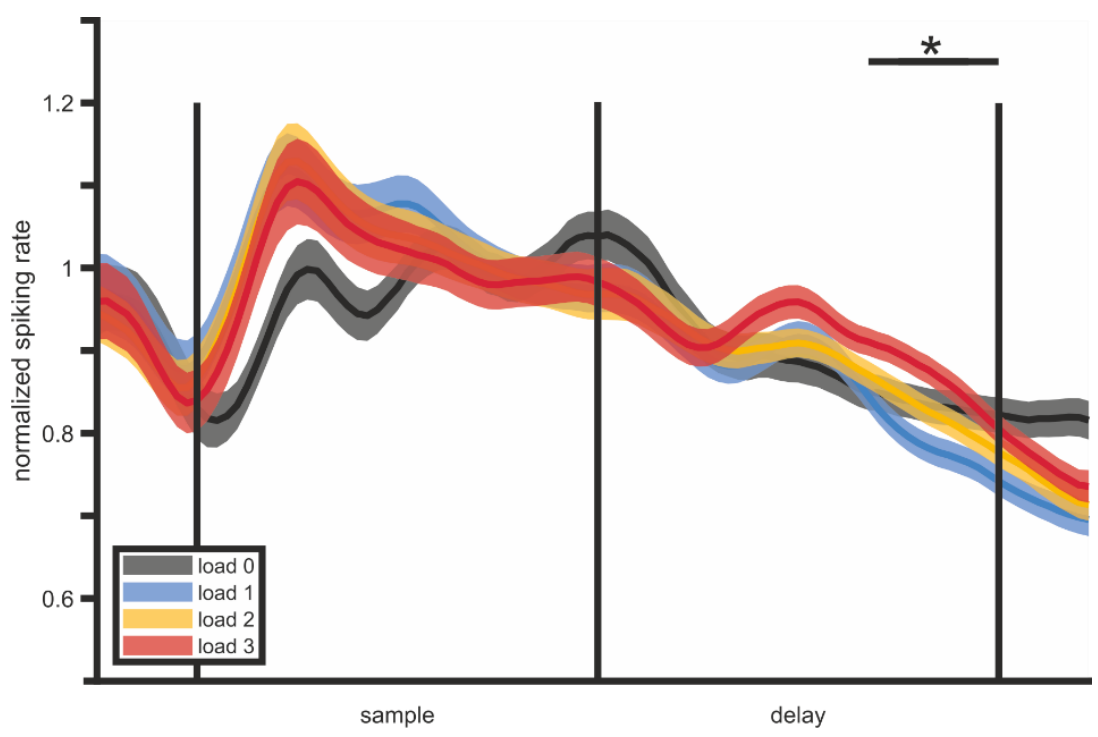

604 SFigure 5: Normalized spiking rate of the neuronal population recorded during the task. The black horizontal bar indicates a significant difference between load conditions.

606 
608

609

610

611

612

613

614

615

616

617

618

619

620

621

622

623

624

625

626

627

628

629

630

631

\section{References}

Baddeley, A. D., \& Hitch, G. (1974). Working Memory. In G. H. Bower (Hrsg.), Psychology of Learning and Motivation (OBB4031-8; Bd. 8, S. 47-89). Academic Press. http://www.sciencedirect.com/science/article/pii/S0079742108604521

Baddeley, A. D., Hitch, G., \& Allen, R. (2021). A Multicomponent Model of Working Memory. In R. H. Logie, V. Camos, \& N. Cowan (Hrsg.), Working Memory State of the Science (First Edition, S. 10-43). Oxford University Press.

Balakhonov, D., \& Rose, J. (2017). Crows Rival Monkeys in Cognitive Capacity. Scientific Reports, 7(1), 8809. https://doi.org/10.1038/s41598-017-09400-0

Banaie Boroujeni, K., Tiesinga, P., \& Womelsdorf, T. (2020). Adaptive spike-artifact removal from local field potentials uncovers prominent beta and gamma band neuronal synchronization. Journal of Neuroscience Methods, 330, 108485. https://doi.org/10.1016/j.jneumeth.2019.108485

Bastos, A. M., Loonis, R., Kornblith, S., Lundqvist, M., \& Miller, E. K. (2018). Laminar recordings in frontal cortex suggest distinct layers for maintenance and control of working memory. Proceedings of the National Academy of Sciences, 115(5), 1117-1122. https://doi.org/10.1073/pnas.1710323115

Benton, M. J., \& Donoghue, P. C. J. (2007). Paleontological Evidence to Date the Tree of Life. Molecular Biology and Evolution, 24(1), 26-53. https://doi.org/10.1093/molbev/msl150

Brainard, D. H. (1997). The psychophysics toolbox. Spatial Vision, 10(4), 433-436. https://doi.org/10.1163/156856897×00357

Brincat, S. L., Donoghue, J. A., Mahnke, M. K., Kornblith, S., Lundqvist, M., \& Miller, E. K. (2021). Interhemispheric transfer of working memories. Neuron, 109(6), 1055-1066.e4. https://doi.org/10.1016/j.neuron.2021.01.016 
632

633

634

635

636

637

638

639

640

641

642

643

644

645

646

647

648

649

650

651

652

653

654

655

656

657

Brown, D. E., Chavez, J. I., Nguyen, D. H., Kadwory, A., Voytek, B., Arneodo, E. M., Gentner, T. Q., \& Gilja, V. (2021). Local field potentials in a pre-motor region predict learned vocal sequences. PLOS Computational Biology, 17(9), e1008100. https://doi.org/10.1371/journal.pcbi.1008100

Buffalo, E. A., Fries, P., Landman, R., Buschman, T. J., \& Desimone, R. (2011). Laminar differences in gamma and alpha coherence in the ventral stream. Proceedings of the National Academy of Sciences, 108(27), 11262-11267. https://doi.org/10.1073/pnas.1011284108

Buschman, T. J., Siegel, M., Roy, J. E., \& Miller, E. K. (2011). Neural substrates of cognitive capacity limitations. Proceedings of the National Academy of Sciences, 108(27), 1125211255. https://doi.org/10.1073/pnas.1104666108

Buzsáki, G., Anastassiou, C. A., \& Koch, C. (2012). The origin of extracellular fields and currents-EEG, ECoG, LFP and spikes. Nature Reviews Neuroscience, 13(6), 407-420. https://doi.org/10.1038/nrn3241

Buzsáki, G., Logothetis, N., \& Singer, W. (2013). Scaling Brain Size, Keeping Timing: Evolutionary Preservation of Brain Rhythms. Neuron, 80(3), 751-764. https://doi.org/10.1016/j.neuron.2013.10.002

Buzsáki, G., \& Wang, X.-J. (2012). Mechanisms of Gamma Oscillations. Annual Review of Neuroscience, 35, 203-225. https://doi.org/10.1146/annurev-neuro-062111-150444

Cardin, J. A., Carlén, M., Meletis, K., Knoblich, U., Zhang, F., Deisseroth, K., Tsai, L.-H., \& Moore, C. I. (2009). Driving fast-spiking cells induces gamma rhythm and controls sensory responses. Nature, 459(7247), 663-667. https://doi.org/10.1038/nature08002

Carlén, M., Meletis, K., Siegle, J. H., Cardin, J. A., Futai, K., Vierling-Claassen, D., Rühlmann, C., Jones, S. R., Deisseroth, K., Sheng, M., Moore, C. I., \& Tsai, L.-H. (2012). A critical role for NMDA receptors in parvalbumin interneurons for gamma rhythm induction and behavior. Molecular Psychiatry, 17(5), 537-548. https://doi.org/10.1038/mp.2011.31 
658

659

660

661

662

663

664

665

666

667

668

669

670

671

672

673

674

675

676

677

678

679

680

681

Constantinidis, C., Funahashi, S., Lee, D., Murray, J. D., Qi, X.-L., Wang, M., \& Arnsten, A. F. T. (2018). Persistent Spiking Activity Underlies Working Memory. Journal of Neuroscience, 38(32), 7020-7028. https://doi.org/10.1523/JNEUROSCI.2486-17.2018

Dheerendra, P., Lynch, N. M., Crutwell, J., Cunningham, M. O., \& Smulders, T. V. (2018). In vitro characterization of gamma oscillations in the hippocampal formation of the domestic chick. European Journal of Neuroscience, 48(8), 2807-2815. https://doi.org/10.1111/ejn.13773

Ditz, H. M., \& Nieder, A. (2016). Numerosity representations in crows obey the Weber-Fechner law. Proceedings of the Royal Society B: Biological Sciences, 283(1827), Article 1827. https://doi.org/10.1098/rspb.2016.0083

Ditz, H. M., \& Nieder, A. (2020). Format-dependent and format-independent representation of sequential and simultaneous numerosity in the crow endbrain. Nature Communications, 11(1), 1-10. https://doi.org/10.1038/s41467-020-14519-2

Einevoll, G. T., Kayser, C., Logothetis, N. K., \& Panzeri, S. (2013). Modelling and analysis of local field potentials for studying the function of cortical circuits. Nature Reviews Neuroscience, 14(11), 770-785. https://doi.org/10.1038/nrn3599

Emery, N. J., \& Clayton, N. S. (2004). The Mentality of Crows: Convergent Evolution of Intelligence in Corvids and Apes. Science, 306(5703), 1903-1907. https://doi.org/10.1126/science.1098410

Fries, P. (2015). Rhythms for Cognition: Communication through Coherence. Neuron, 88(1), 220-235. https://doi.org/10.1016/j.neuron.2015.09.034

Gibson, B., Wasserman, E., \& Luck, S. J. (2011). Qualitative similarities in the visual short-term memory of pigeons and people. Psychonomic Bulletin \& Review, 18(5), 979. https://doi.org/10.3758/s13423-011-0132-7 
682

683

684

685

686

687

688

689

690

691

692

693

694

695

696

697

698

699

700

701

702

703

704

705

706

Goddard, C. A., Sridharan, D., Huguenard, J. R., \& Knudsen, E. I. (2012). Gamma Oscillations Are Generated Locally in an Attention-Related Midbrain Network. Neuron, 73(3), 567580. https://doi.org/10.1016/j.neuron.2011.11.028

Güntürkün, O., \& Bugnyar, T. (2016). Cognition without Cortex. Trends in Cognitive Sciences, 20(4), 291-303. https://doi.org/10.1016/j.tics.2016.02.001

Güntürkün, O., Stacho, M., \& Ströckens, F. (2020). The Brains of Reptiles and Birds. In J. H. Kaas (Hrsg.), Evolutionary Neuroscience (Second Edition) (S. 159-212). Academic

Press. https://www.sciencedirect.com/science/article/pii/B9780128205846000088

Hahn, L. A., Balakhonov, D., Fongaro, E., Nieder, A., \& Rose, J. (2021). Working memory capacity of crows and monkeys arises from similar neuronal computations. eLife, 10, e72783. https://doi.org/10.7554/eLife.72783

Händel, B. F., Haarmeier, T., \& Jensen, O. (2011). Alpha Oscillations Correlate with the Successful Inhibition of Unattended Stimuli. Journal of Cognitive Neuroscience, 23(9), 2494-2502. https://doi.org/10.1162/jocn.2010.21557

Harris, K. D., \& Shepherd, G. M. G. (2015). The neocortical circuit: Themes and variations. Nature Neuroscience, 18(2), 170-181. https://doi.org/10.1038/nn.3917

Herold, C., Palomero-Gallagher, N., Hellmann, B., Kroner, S., Theiss, C., Güntürkün, O., \& Zilles, K. (2011). The receptor architecture of the pigeons' nidopallium caudolaterale: An avian analogue to the mammalian prefrontal cortex. Brain Structure \& Function, 216(3), 239-254. https://doi.org/10.1007/s00429-011-0301-5

Honig, W. K. (1978). Studies of Working Memory in the Pigeon. In Cognitive Processes in Animal Cognition, Stewart H. Hulse, Harry Fowler, Werner K. Honig (eds.) (S. 211-248). Lawrence Erlbaum Associates, Inc.

Howard, M. W., Rizzuto, D. S., Caplan, J. B., Madsen, J. R., Lisman, J., AschenbrennerScheibe, R., Schulze-Bonhage, A., \& Kahana, M. J. (2003). Gamma Oscillations 
Correlate with Working Memory Load in Humans. Cerebral Cortex, 13(12), 1369-1374. https://doi.org/10.1093/cercor/bhg084

Husband, S., \& Shimizu, T. (2001). Evolution of the Avian Visual System. In Avian visual cognition [On-line]. Available: Pigeon.psy.tufts.edu/avc/husband/. http://www.pigeon.psy.tufts.edu/avc/husband/

Jensen, O., \& Mazaheri, A. (2010). Shaping Functional Architecture by Oscillatory Alpha Activity: Gating by Inhibition. Frontiers in Human Neuroscience, 4, 186. https://doi.org/10.3389/fnhum.2010.00186

Kornblith, S., Buschman, T. J., \& Miller, E. K. (2016). Stimulus Load and Oscillatory Activity in Higher Cortex. Cerebral Cortex, 26(9), 3772-3784. https://doi.org/10.1093/cercor/bhv182

Kröner, S., \& Güntürkün, O. (1999). Afferent and efferent connections of the caudolateral neostriatum in the pigeon (Columba livia): A retro- and anterograde pathway tracing study. Journal of Comparative Neurology, 407(2), 228-260. https://doi.org/10.1002/(sici)1096-9861(19990503)407:2<228::aid-cne6>3.0.co;2-2

Kucewicz, M. T., Berry, B. M., Kremen, V., Brinkmann, B. H., Sperling, M. R., Jobst, B. C., Gross, R. E., Lega, B., Sheth, S. A., Stein, J. M., Das, S. R., Gorniak, R., Stead, S. M., Rizzuto, D. S., Kahana, M. J., \& Worrell, G. A. (2017). Dissecting gamma frequency activity during human memory processing. Brain, 140(5), 1337-1350. https://doi.org/10.1093/brain/awx043

Lewandowski, B. C., \& Schmidt, M. (2011). Short Bouts of Vocalization Induce Long-Lasting Fast Gamma Oscillations in a Sensorimotor Nucleus. Journal of Neuroscience, 31(39), 13936-13948. https://doi.org/10.1523/JNEUROSCI.6809-10.2011

Lisman, J. E. (1997). Bursts as a unit of neural information: Making unreliable synapses reliable. Trends in Neurosciences, 20(1), 38-43. https://doi.org/10.1016/S0166-2236(96)10070-9 
732

733

734

735

736

737

738

739

740

741

742

743

744

745

746

747

748

749

750

751

752

753

754

755

756

Lundqvist, M., Compte, A., \& Lansner, A. (2010). Bistable, Irregular Firing and Population Oscillations in a Modular Attractor Memory Network. PLOS Computational Biology, 6(6), e1000803. https://doi.org/10.1371/journal.pcbi.1000803

Lundqvist, M., Herman, P., \& Lansner, A. (2011). Theta and Gamma Power Increases and Alpha/Beta Power Decreases with Memory Load in an Attractor Network Model. Journal of Cognitive Neuroscience, 23(10), 3008-3020. https://doi.org/10.1162/jocn_a_00029

Lundqvist, M., Herman, P., \& Miller, E. K. (2018). Working Memory: Delay Activity, Yes! Persistent Activity? Maybe Not. Journal of Neuroscience, 38(32), 7013-7019. https://doi.org/10.1523/JNEUROSCI.2485-17.2018

Lundqvist, M., Herman, P., Warden, M. R., Brincat, S. L., \& Miller, E. K. (2018). Gamma and beta bursts during working memory readout suggest roles in its volitional control. Nature Communications, 9(1), 394. https://doi.org/10.1038/s41467-017-02791-8

Lundqvist, M., Rose, J., Herman, P., Brincat, S. L., Buschman, T. J., \& Miller, E. K. (2016). Gamma and Beta Bursts Underlie Working Memory. Neuron, 90(1), 152-164. https://doi.org/10.1016/j.neuron.2016.02.028

Maier, A., Adams, G., Aura, C., \& Leopold, D. (2010). Distinct Superficial and Deep Laminar Domains of Activity in the Visual Cortex during Rest and Stimulation. Frontiers in Systems Neuroscience, 4. https://www.frontiersin.org/article/10.3389/fnsys.2010.00031

Meltzer, J. A., Zaveri, H. P., Goncharova, I. I., Distasio, M. M., Papademetris, X., Spencer, S. S., Spencer, D. D., \& Constable, R. T. (2008). Effects of Working Memory Load on Oscillatory Power in Human Intracranial EEG. Cerebral Cortex, 18(8), 1843-1855. https://doi.org/10.1093/cercor/bhm213

Merker, B. (2013). Cortical gamma oscillations: The functional key is activation, not cognition. Neuroscience \& Biobehavioral Reviews, 37(3), 401-417. https://doi.org/10.1016/j.neubiorev.2013.01.013 
Miller, E. K., Lundqvist, M., \& Bastos, A. M. (2018). Working Memory 2.0. Neuron, 100(2), 463475. https://doi.org/10.1016/j.neuron.2018.09.023

Moll, F. W., \& Nieder, A. (2015). Cross-Modal Associative Mnemonic Signals in Crow Endbrain Neurons. Current Biology, 25(16), 2196-2201. https://doi.org/10.1016/j.cub.2015.07.013 Mongillo, G., Barak, O., \& Tsodyks, M. (2008). Synaptic Theory of Working Memory. Science. https://doi.org/10.1126/science.1150769

Naud, R., \& Sprekeler, H. (2018). Sparse bursts optimize information transmission in a multiplexed neural code. Proceedings of the National Academy of Sciences, 115(27), E6329-E6338. https://doi.org/10.1073/pnas.1720995115

Neuenschwander, S., \& Varela, F. J. (1993). Visually Triggered Neuronal Oscillations in the Pigeon: An Autocorrelation Study of Tectal Activity. European Journal of Neuroscience, 5(7), 870-881. https://doi.org/10.1111/j.1460-9568.1993.tb00939.x

Nieder, A. (2017). Inside the corvid brain-Probing the physiology of cognition in crows. Current Opinion in Behavioral Sciences, 16, 8-14. https://doi.org/10.1016/j.cobeha.2017.02.005

Oostenveld, R., Fries, P., Maris, E., \& Schoffelen, J.-M. (2010). FieldTrip: Open Source Software for Advanced Analysis of MEG, EEG, and Invasive Electrophysiological Data. Computational Intelligence and Neuroscience, 2011, e156869. https://doi.org/10.1155/2011/156869

Panichello, M. F., \& Buschman, T. J. (2021). Shared mechanisms underlie the control of working memory and attention. Nature, 1-5. https://doi.org/10.1038/s41586-021-03390W

Ray, S., \& Maunsell, J. H. R. (2015). Do gamma oscillations play a role in cerebral cortex? Trends in Cognitive Sciences, 19(2), 78-85. https://doi.org/10.1016/j.tics.2014.12.002 Rinnert, P., Kirschhock, M. E., \& Nieder, A. (2019). Neuronal Correlates of Spatial Working Memory in the Endbrain of Crows. Current Biology, 29(16), 2616-2624.e4. https://doi.org/10.1016/j.cub.2019.06.060 
783

784

785

786

787

788

789

790

791

792

793

794

795

796

797

798

799

800

801

802

803

804

805

806

807

Rose, J., \& Colombo, M. (2005). Neural correlates of executive control in the avian brain. Plos

Biology, 3(6), 1139-1146. https://doi.org/10.1371/journal.pbio.0030190

Rose, J., Otto, T., \& Dittrich, L. (2008). The Biopsychology-Toolbox: A free, open-source Matlab-toolbox for the control of behavioral experiments. Journal of Neuroscience Methods, 175(1), 104-107. https://doi.org/10.1016/j.jneumeth.2008.08.006

Roux, F., Wibral, M., Mohr, H. M., Singer, W., \& Uhlhaas, P. J. (2012). Gamma-Band Activity in Human Prefrontal Cortex Codes for the Number of Relevant Items Maintained in Working Memory. Journal of Neuroscience, 32(36), 12411-12420. https://doi.org/10.1523/JNEUROSCI.0421-12.2012

Sandberg, A., Tegnér, J., \& Lansner, A. (2003). A working memory model based on fast Hebbian learning. Network: Computation in Neural Systems, 14(4), 789-802. https://doi.org/10.1088/0954-898X/14/4/309

Sederberg, P. B., Kahana, M. J., Howard, M. W., Donner, E. J., \& Madsen, J. R. (2003). Theta and Gamma Oscillations during Encoding Predict Subsequent Recall. Journal of Neuroscience, 23(34), 10809-10814. https://doi.org/10.1523/JNEUROSCI.23-3410809.2003

Spool, J. A., Macedo-Lima, M., Scarpa, G., Morohashi, Y., Yazaki-Sugiyama, Y., \& RemageHealey, L. (2021). Genetically identified neurons in avian auditory pallium mirror core principles of their mammalian counterparts. Current Biology, 31(13), 2831-2843.e6. https://doi.org/10.1016/j.cub.2021.04.039

Sreenivasan, K. K., \& D’Esposito, M. (2019). The what, where and how of delay activity. Nature Reviews Neuroscience, 20(8), 466-481. https://doi.org/10.1038/s41583-019-0176-7

Sridharan, D., Boahen, K., \& Knudsen, E. I. (2011). Space coding by gamma oscillations in the barn owl optic tectum. Journal of Neurophysiology, 105(5), 2005-2017. https://doi.org/10.1152/jn.00965.2010 
808

809

810

811

812

813

814

815

816

817

818

819

820

821

822

823

824

825

826

827

828

829

830

831

832

833

Sridharan, D., \& Knudsen, E. I. (2015). Gamma oscillations in the midbrain spatial attention network: Linking circuits to function. Current Opinion in Neurobiology, 31, 189-198. https://doi.org/10.1016/j.conb.2014.11.006

Stacho, M., Herold, C., Rook, N., Wagner, H., Axer, M., Amunts, K., \& Güntürkün, O. (2020). A cortex-like canonical circuit in the avian forebrain. Science, 369(6511), Article 6511. https://doi.org/10.1126/science.abc5534

Tallon-Baudry, C., Bertrand, O., Peronnet, F., \& Pernier, J. (1998). Induced Y-Band Activity during the Delay of a Visual Short-Term Memory Task in Humans. Journal of Neuroscience, 18(11), 4244-4254. https://doi.org/10.1523/JNEUROSCI.18-1104244.1998

Traub, R. D., Whittington, M. A., Stanford, I. M., \& Jefferys, J. G. R. (1996). A mechanism for generation of long-range synchronous fast oscillations in the cortex. Nature, 383(6601), 621-624. https://doi.org/10.1038/383621a0

Troscianko, J., von Bayern, A. M. P., Chappell, J., Rutz, C., \& Martin, G. R. (2012). Extreme binocular vision and a straight bill facilitate tool use in New Caledonian crows. Nature Communications, 3(1), 1110. https://doi.org/10.1038/ncomms2111

van der Meij, J., Rattenborg, N. C., \& Beckers, G. J. L. (2020). Divergent neuronal activity patterns in the avian hippocampus and nidopallium. European Journal of Neuroscience, 52(4), 3124-3139. https://doi.org/10.1111/ejn.14675

Veit, L., \& Nieder, A. (2013). Abstract rule neurons in the endbrain support intelligent behaviour in corvid songbirds. Nature Communications, 4, 11. https://doi.org/10.1038/ncomms3878

Waldmann, C., \& Güntürkün, O. (1993). The dopaminergic innervation of the pigeon caudolateral forebrain-Immunocytochemical evidence for a prefrontal cortex in birds. Brain Research, 600(2), 225-234. https://doi.org/10.1016/0006-8993(93)91377-5

Wang, X.-J. (2021). 50 years of mnemonic persistent activity: Quo vadis? Trends in Neurosciences, 44(11), 888-902. https://doi.org/10.1016/j.tins.2021.09.001 


\section{Acknowledgments}

835 We would like to thank Robert Schmidt for helpful comments on an earlier draft of the manuscript.

\section{Author contributions}

837 Lukas Alexander Hahn, Data curation, Formal analysis, Investigation, Methodology, Software, 838 Visualization, Writing - original draft, Writing - review and editing; Dmitry Balakhonov, 839 Conceptualization, Data collection, Methodology; Mikael Lundqvist, Investigation, Visualization, 840 Writing - review and editing; Andreas Nieder, Project administration, Resources, Writing - review 841 and editing; Jonas Rose, Conceptualization, Funding acquisition, Methodology, Project

842 administration, Resources, Supervision, Visualization, Writing - review and editing

843 Declaration of interests

844 The authors declare no competing interests.

\section{Funding}

846 This research was supported by a Volkswagen Foundation Freigeist Fellowship (93299) awarded

847 to J.R. and by Deutsche Forschungsgemeinschaft Project B13 of the collaborative research 848 center 874 (122679504). The funders had no role in study design, data collection, interpretation, 849 or the decision to submit the work for publication. 
bioRxiv preprint doi: https://doi.org/10.1101/2022.02.01.478165; this version posted February 2, 2022. The copyright holder for this preprint (which was not certified by peer review) is the author/funder, who has granted bioRxiv a license to display the preprint in perpetuity. It is made

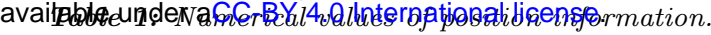

\begin{tabular}{|c|c|c|c|c|c|c|}
\hline & \multicolumn{6}{|c|}{ average position information contralateral $\left(R_{a d j .}^{2}\right)$} \\
\hline frequency & preSmp & earlySmp & lateSmp & earlyDly & midDly & lateDly \\
\hline$\theta(3-7 H z)$ & 0.0001 & 0.0045 & 0.0096 & 0.0059 & 0.008 & 0.0046 \\
\hline$\alpha(8-12 H z)$ & 0 & 0.0067 & 0.0088 & 0.0048 & 0.007 & 0.0037 \\
\hline$\beta(13-19 H z)$ & 0.0008 & 0.0049 & 0.0065 & 0.0025 & 0.0121 & 0.0042 \\
\hline$\gamma(33-48 H z)$ & 0.0004 & 0.0182 & 0.033 & 0.0073 & 0.0064 & 0.0017 \\
\hline \multirow[t]{2}{*}{$\Gamma(83-98 H z)$} & -0.0003 & 0.0127 & 0.0152 & 0.0049 & 0.0028 & 0.0053 \\
\hline & \multicolumn{6}{|c|}{ standard error of the mean (contralateral) } \\
\hline$\theta(3-7 H z)$ & 0.0003 & 0.0006 & 0.001 & 0.0009 & 0.0009 & 0.0006 \\
\hline$\alpha(8-12 H z)$ & 0.0003 & 0.0009 & 0.0011 & 0.0007 & 0.0008 & 0.0005 \\
\hline$\beta(13-19 H z)$ & 0.0004 & 0.0007 & 0.0008 & 0.0005 & 0.0011 & 0.0005 \\
\hline$\gamma(33-48 H z)$ & 0.0003 & 0.0019 & 0.002 & 0.0007 & 0.0007 & 0.0005 \\
\hline \multirow[t]{2}{*}{$\Gamma(83-98 H z)$} & 0.0003 & 0.0021 & 0.0012 & 0.0007 & 0.0006 & 0.0007 \\
\hline & \multicolumn{6}{|c|}{ effect size of test against null distribution $\left(\omega^{2}\right)$} \\
\hline$\theta(3-7 H z)$ & -0.0006 & 0.1584 & 0.2323 & 0.1274 & 0.21 & 0.1384 \\
\hline$\alpha(8-12 H z)$ & -0.0006 & 0.142 & 0.1811 & 0.1409 & 0.1899 & 0.1307 \\
\hline$\beta(13-19 H z)$ & 0.0138 & 0.1374 & 0.1928 & 0.0691 & 0.2993 & 0.1716 \\
\hline$\gamma(33-48 H z)$ & 0.0044 & 0.2327 & 0.4597 & 0.2584 & 0.2159 & 0.0419 \\
\hline \multirow[t]{2}{*}{$\Gamma(83-98 H z)$} & 0.0014 & 0.1092 & 0.3477 & 0.1384 & 0.063 & 0.1576 \\
\hline & \multicolumn{6}{|c|}{ average position information ipsilateral $\left(R_{a d j .}^{2}\right)$} \\
\hline$\theta(3-7 H z)$ & -0.0013 & 0.0013 & 0.0017 & 0.0058 & 0.0034 & 0.0018 \\
\hline$\alpha(8-12 H z)$ & 0.0006 & 0.003 & 0.0013 & 0.0016 & 0.0005 & 0.0004 \\
\hline$\beta(13-19 H z)$ & 0.0005 & 0.0017 & 0.0021 & 0.0004 & -0.0001 & 0.0004 \\
\hline$\gamma(33-48 H z)$ & 0.0001 & 0.0006 & 0.0029 & 0.0025 & 0.0008 & 0.0007 \\
\hline \multirow[t]{2}{*}{$\Gamma(83-98 H z)$} & -0.0001 & 0.0016 & 0.0009 & 0.0014 & 0.0007 & 0.0015 \\
\hline & \multicolumn{6}{|c|}{ standard error of the mean (ipsilateral) } \\
\hline$\theta(3-7 H z)$ & 0.0003 & 0.0005 & 0.0005 & 0.0007 & 0.0007 & 0.0004 \\
\hline$\alpha(8-12 H z)$ & 0.0004 & 0.0005 & 0.0004 & 0.0005 & 0.0004 & 0.0004 \\
\hline$\beta(13-19 H z)$ & 0.0003 & 0.0004 & 0.0004 & 0.0004 & 0.0003 & 0.0004 \\
\hline$\gamma(33-48 H z)$ & 0.0004 & 0.0004 & 0.0004 & 0.0005 & 0.0004 & 0.0003 \\
\hline \multirow[t]{2}{*}{$\Gamma(83-98 H z)$} & 0.0003 & 0.0005 & 0.0004 & 0.0005 & 0.0004 & 0.0004 \\
\hline & \multicolumn{6}{|c|}{ effect size of test against null distribution $\left(\omega^{2}\right)$} \\
\hline$\theta(3-7 H z)$ & 0.0689 & 0.0218 & 0.0399 & 0.196 & 0.0736 & 0.0566 \\
\hline$\alpha(8-12 H z)$ & 0.0072 & 0.1012 & 0.0256 & 0.0352 & 0.0055 & 0.0042 \\
\hline$\beta(13-19 H z)$ & 0.0092 & 0.0531 & 0.0695 & 0.0033 & -0.0005 & 0.0033 \\
\hline$\gamma(33-48 H z)$ & -0.0007 & 0.0051 & 0.1166 & 0.0801 & 0.0123 & 0.0125 \\
\hline$\Gamma(83-98 H z)$ & -0.0005 & 0.0376 & 0.0172 & 0.025 & 0.0097 & 0.038 \\
\hline
\end{tabular}


bioRxiv preprint doi: https://doi.org/10.1101/2022.02.01.478165; this version posted February 2, 2022. The copyright holder for this preprint (which was not certified by peer review) is the author/funder, who has granted bioRxiv a license to display the preprint in perpetuity. It is made

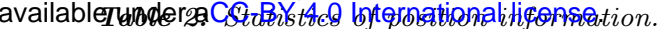

\begin{tabular}{|c|c|c|c|c|}
\hline ID & $\mathrm{F}$ & $d f_{1}$ & $d f_{2}$ & $\mathrm{p}$ \\
\hline$\theta(3-7 H z)$ contraPreSmp & 0.3103 & 1 & 1247 & 0.5776 \\
\hline$\theta(3-7 H z)$ contraEarlySmp & 236.1105 & 1 & 1247 & $<0.0001$ \\
\hline$\theta(3-7 H z)$ contraLateSmp & 378.9953 & 1 & 1247 & $<0.0001$ \\
\hline$\theta(3-7 H z)$ contraEarlyDly & 183.325 & 1 & 1247 & $<0.0001$ \\
\hline$\theta(3-7 H z)$ contraMidDly & 332.9131 & 1 & 1247 & $<0.0001$ \\
\hline$\theta(3-7 H z)$ contraLateDlyEarlyChc & 201.582 & 1 & 1247 & $<0.0001$ \\
\hline$\theta(3-7 H z)$ ipsiPreSmp & 93.4328 & 1 & 1247 & $<0.0001$ \\
\hline$\theta(3-7 H z)$ ipsiEarlySmp & 28.8243 & 1 & 1247 & $<0.0001$ \\
\hline$\theta(3-7 H z)$ ipsiLateSmp & 52.9692 & 1 & 1247 & $<0.0001$ \\
\hline$\theta(3-7 H z)$ ipsiEarlyDly & 305.5275 & 1 & 1247 & $<0.0001$ \\
\hline$\theta(3-7 H z)$ ipsiMidDly & 100.2107 & 1 & 1247 & $<0.0001$ \\
\hline$\theta(3-7 H z)$ ipsiLateDlyEarlyChc & 75.9505 & 1 & 1247 & $<0.0001$ \\
\hline$\alpha(8-12 H z)$ contraPreSmp & 0.196 & 1 & 1247 & 0.6581 \\
\hline$\alpha(8-12 H z)$ contraEarlySmp & 207.6518 & 1 & 1247 & $<0.0001$ \\
\hline$\alpha(8-12 H z)$ contraLateSmp & 277.1249 & 1 & 1247 & $<0.0001$ \\
\hline$\alpha(8-12 H z)$ contraEarlyDly & 205.7884 & 1 & 1247 & $<0.0001$ \\
\hline$\alpha(8-12 H z)$ contraMidDly & 293.8236 & 1 & 1247 & $<0.0001$ \\
\hline$\alpha(8-12 H z)$ contraLateDlyEarlyChc & 188.7494 & 1 & 1247 & $<0.0001$ \\
\hline$\alpha(8-12 H z)$ ipsiPreSmp & 10.015 & 1 & 1247 & 0.0016 \\
\hline$\alpha(8-12 H z)$ ipsiEarlySmp & 141.6304 & 1 & 1247 & $<0.0001$ \\
\hline$\alpha(8-12 H z)$ ipsiLateSmp & 33.8392 & 1 & 1247 & $<0.0001$ \\
\hline$\alpha(8-12 H z)$ ipsiEarlyDly & 46.5335 & 1 & 1247 & $<0.0001$ \\
\hline$\alpha(8-12 H z)$ ipsiMidDly & 7.9221 & 1 & 1247 & 0.005 \\
\hline$\alpha(8-12 H z)$ ipsiLateDlyEarlyChc & 6.2923 & 1 & 1247 & 0.0123 \\
\hline$\beta(13-19 H z)$ contraPreSmp & 18.4705 & 1 & 1247 & $<0.0001$ \\
\hline$\beta(13-19 H z)$ contraEarlySmp & 200.0195 & 1 & 1247 & $<0.0001$ \\
\hline$\beta(13-19 H z)$ contraLateSmp & 299.3604 & 1 & 1247 & $<0.0001$ \\
\hline$\beta(13-19 H z)$ contraEarlyDly & 93.7528 & 1 & 1247 & $<0.0001$ \\
\hline$\beta(13-19 H z)$ contraMidDly & 534.4364 & 1 & 1247 & $<0.0001$ \\
\hline$\beta(13-19 H z)$ contraLateDlyEarlyChc & 259.699 & 1 & 1247 & $<0.0001$ \\
\hline$\beta(13-19 H z)$ ipsiPreSmp & 12.6119 & 1 & 1247 & 0.0004 \\
\hline$\beta(13-19 H z)$ ipsiEarlySmp & 71.0949 & 1 & 1247 & $<0.0001$ \\
\hline$\beta(13-19 H z)$ ipsiLateSmp & 94.2461 & 1 & 1247 & $<0.0001$ \\
\hline$\beta(13-19 H z)$ ipsiEarlyDly & 5.0947 & 1 & 1247 & 0.0242 \\
\hline$\beta(13-19 H z)$ ipsiMidDly & 0.4002 & 1 & 1247 & 0.5271 \\
\hline$\beta(13-19 H z)$ ipsiLateDlyEarlyChc & 5.1808 & 1 & 1247 & 0.023 \\
\hline$\gamma(33-48 H z)$ contraPreSmp & 6.4733 & 1 & 1247 & 0.0111 \\
\hline$\gamma(33-48 H z)$ contraEarlySmp & 379.8323 & 1 & 1247 & $<0.0001$ \\
\hline$\gamma(33-48 H z)$ contraLateSmp & 1063.827 & 1 & 1247 & $<0.0001$ \\
\hline$\gamma(33-48 H z)$ contraEarlyDly & 436.2718 & 1 & 1247 & $<0.0001$ \\
\hline$\gamma(33-48 H z)$ contraMidDly & 344.8669 & 1 & 1247 & $<0.0001$ \\
\hline$\gamma(33-48 H z)$ contraLateDlyEarlyChc & 55.5925 & 1 & 1247 & $<0.0001$ \\
\hline$\gamma(33-48 H z)$ ipsiPreSmp & 0.1014 & 1 & 1247 & 0.7502 \\
\hline$\gamma(33-48 H z)$ ipsiEarlySmp & 7.44 & 1 & 1247 & 0.0065 \\
\hline$\gamma(33-48 H z)$ ipsiLateSmp & 165.8605 & 1 & 1247 & $<0.0001$ \\
\hline$\gamma(33-48 H z)$ ipsiEarlyDly & 109.7774 & 1 & 1247 & $<0.0001$ \\
\hline$\gamma(33-48 H z)$ ipsiMidDly & 16.5156 & 1 & 1247 & $<0.0001$ \\
\hline$\gamma(33-48 H z)$ ipsiLateDlyEarlyChc & 16.8524 & 1 & 1247 & $<0.0001$ \\
\hline
\end{tabular}


bioRxiv preprint doi: https://doi.org/10.1101/2022.02.01.478165; this version posted February 2, 2022. The copyright holder for this preprint (which was not certified by peer review) is the author/funder, who has granted bioRxiv a license to display the preprint in perpetuity. It is made

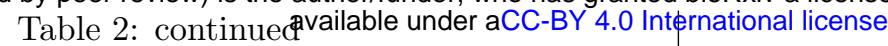

$\Gamma(83-98 \mathrm{~Hz})$ contraPreSmp
$\Gamma(83-98 \mathrm{~Hz})$ contraEarlySmp
$\Gamma(83-98 \mathrm{~Hz})$ contraLateSmp
$\Gamma(83-98 \mathrm{~Hz})$ contraEarlyDly
$\Gamma(83-98 \mathrm{~Hz})$ contraMidDly
$\Gamma(83-98 \mathrm{~Hz})$ contraLateDlyEarlyChc
$\Gamma(83-98 \mathrm{~Hz})$ ipsiPreSmp
$\Gamma(83-98 \mathrm{~Hz})$ ipsiEarlySmp
$\Gamma(83-98 \mathrm{~Hz})$ ipsiLateSmp
$\Gamma(83-98 \mathrm{~Hz})$ ipsiEarlyDly
$\Gamma(83-98 \mathrm{~Hz})$ ipsiMidDly
$\Gamma(83-98 \mathrm{~Hz})$ ipsiLateDlyEarlyChc

2.7801

154.0675

666.6498

201.7003

85.0001

234.6346

0.3795

49.7564

22.8253

32.9647

13.1832

50.3882
$1247 \quad 0.0957$

$1247<0.0001$

$1247<0.0001$

$1247<0.0001$

$1247<0.0001$

$1247<0.0001$

$1247 \quad 0.538$

$1247<0.0001$

$1247<0.0001$

$1247<0.0001$

$1247 \quad 0.0003$

$1247<0.0001$ 
bioRxiv preprint doi: https://doi.org/10.1101/2022.02.01.478165; this version posted February 2, 2022. The copyright holder for this preprint (which was not certified by peer review) is the author/funder, who has granted bioRxiv a license to display the preprint in perpetuity. It is made

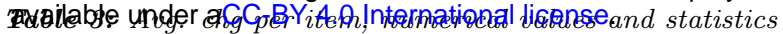

\begin{tabular}{|c|c|}
\hline $\begin{array}{l}\text { bin start relative to } \\
\text { sample on }(\mathrm{ms})\end{array}$ & avg. chg. per item $\left(* 10^{-2} \%\right) \pm$ SEM, test vs. 0 ; effect size of factor load \\
\hline \multicolumn{2}{|l|}{$\theta(3-7 H z)$} \\
\hline-200 & $-0.0002 \pm 0.028, \mathrm{t}(288)=0.01833, \mathrm{p}=0.9854 ; \omega^{2}=0.0059$ \\
\hline-100 & $0.0016 \pm 0.0235, \mathrm{t}(288)=-0.18974, \mathrm{p}=0.8496 ; \omega^{2}=0.0032$ \\
\hline 0 & $0.0055 \pm 0.0202, \mathrm{t}(288)=-0.74963, \mathrm{p}=0.4541 ; \omega^{2}=-0.0017$ \\
\hline 100 & $0.008 \pm 0.017, \mathrm{t}(288)=-1.2945, \mathrm{p}=0.1965 ; \omega^{2}=-0.0026$ \\
\hline 200 & $0.0095 \pm 0.014, \mathrm{t}(288)=-1.8655, \mathrm{p}=0.0631 ; \omega^{2}=0.002$ \\
\hline 300 & $0.0103 \pm 0.0122, \mathrm{t}(288)=-2.3301, \mathrm{p}=0.0205 ; \omega^{2}=0.0019$ \\
\hline 400 & $0.0124 \pm 0.0129, \mathrm{t}(288)=-2.6689, \mathrm{p}=0.008 ; \omega^{2}=-0.0262$ \\
\hline 500 & $0.0198 \pm 0.0155, \mathrm{t}(288)=-3.5227, \mathrm{p}=0.0005 ; \omega^{2}=-0.0374$ \\
\hline 600 & $0.0318 \pm 0.0174, \mathrm{t}(288)=-5.039, \mathrm{p}<0.0001 ; \omega^{2}=-0.0126$ \\
\hline 700 & $0.0429 \pm 0.0169, \mathrm{t}(288)=-6.9947, \mathrm{p}<0.0001 ; \omega^{2}=0.0209$ \\
\hline 800 & $0.0486 \pm 0.015, \mathrm{t}(288)=-8.9559, \mathrm{p}<0.0001 ; \omega^{2}=0.0412$ \\
\hline 900 & $0.0492 \pm 0.0131, \mathrm{t}(288)=-10.3168, \mathrm{p}<0.0001 ; \omega^{2}=0.045$ \\
\hline 1000 & $0.0487 \pm 0.0122, \mathrm{t}(288)=-11.0283, \mathrm{p}<0.0001 ; \omega^{2}=0.0465$ \\
\hline 1100 & $0.0517 \pm 0.0122, \mathrm{t}(288)=-11.7262, \mathrm{p}<0.0001 ; \omega^{2}=0.0584$ \\
\hline 1200 & $0.0592 \pm 0.0129, \mathrm{t}(288)=-12.6267, \mathrm{p}<0.0001 ; \omega^{2}=0.0865$ \\
\hline 1300 & $0.0718 \pm 0.0144, \mathrm{t}(288)=-13.7098, \mathrm{p}<0.0001 ; \omega^{2}=0.1366$ \\
\hline 1400 & $0.0918 \pm 0.0168, \mathrm{t}(288)=-15.0213, \mathrm{p}<0.0001 ; \omega^{2}=0.2025$ \\
\hline 1500 & $0.1182 \pm 0.0197, \mathrm{t}(288)=-16.537, \mathrm{p}<0.0001 ; \omega^{2}=0.2471$ \\
\hline 1600 & $0.1423 \pm 0.0226, \mathrm{t}(288)=-17.3278, \mathrm{p}<0.0001 ; \omega^{2}=0.2502$ \\
\hline 1700 & $0.1503 \pm 0.0248, \mathrm{t}(288)=-16.7352, \mathrm{p}<0.0001 ; \omega^{2}=0.2248$ \\
\hline 1800 & $0.1339 \pm 0.0245, \mathrm{t}(288)=-15.0652, \mathrm{p}<0.0001 ; \omega^{2}=0.1833$ \\
\hline 1900 & $0.1003 \pm 0.0242, \mathrm{t}(288)=-11.4106, \mathrm{p}<0.0001 ; \omega^{2}=0.1308$ \\
\hline 2000 & $0.0714 \pm 0.0297, \mathrm{t}(288)=-6.6298, \mathrm{p}<0.0001 ; \omega^{2}=0.0859$ \\
\hline 2100 & $0.0537 \pm 0.0334, \mathrm{t}(287)=-4.4192, \mathrm{p}<0.0001 ; \omega^{2}=0.0529$ \\
\hline \multicolumn{2}{|r|}{ 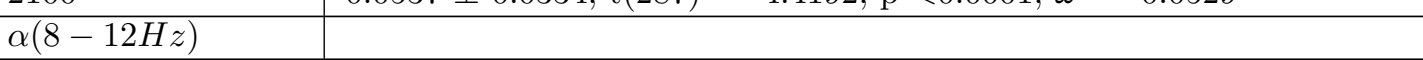 } \\
\hline-200 & $-0.0004 \pm 0.0257, \mathrm{t}(268)=0.038799, \mathrm{p}=0.9691 ; \omega^{2}=0.006$ \\
\hline-100 & $0.01 \pm 0.0215, \mathrm{t}(268)=-1.2311, \mathrm{p}=0.2194 ; \omega^{2}=0.0003$ \\
\hline 0 & $0.0217 \pm 0.0187, \mathrm{t}(269)=-3.0882, \mathrm{p}=0.0022 ; \omega^{2}=0.0034$ \\
\hline 100 & $0.0276 \pm 0.015, \mathrm{t}(269)=-4.9084, \mathrm{p}<0.0001 ; \omega^{2}=0.0289$ \\
\hline 200 & $0.0352 \pm 0.0133, \mathrm{t}(269)=-7.0544, \mathrm{p}<0.0001 ; \omega^{2}=0.0197$ \\
\hline 300 & $0.0227 \pm 0.0147, \mathrm{t}(269)=-4.1294, \mathrm{p}<0.0001 ; \omega^{2}=0.0056$ \\
\hline 400 & $0.0112 \pm 0.0209, \mathrm{t}(269)=-1.4248, \mathrm{p}=0.1554 ; \omega^{2}=-0.0133$ \\
\hline 500 & $0.0154 \pm 0.0264, \mathrm{t}(269)=-1.5565, \mathrm{p}=0.1208 ; \omega^{2}=-0.0437$ \\
\hline 600 & $0.034 \pm 0.0305, \mathrm{t}(269)=-2.9688, \mathrm{p}=0.0033 ; \omega^{2}=-0.0223$ \\
\hline 700 & $0.0521 \pm 0.0292, \mathrm{t}(269)=-4.7633, \mathrm{p}<0.0001 ; \omega^{2}=0.0062$ \\
\hline 800 & $0.065 \pm 0.021, \mathrm{t}(269)=-8.2519, \mathrm{p}<0.0001 ; \omega^{2}=0.0199$ \\
\hline 900 & $0.0681 \pm 0.016, \mathrm{t}(269)=-11.324, \mathrm{p}<0.0001 ; \omega^{2}=0.048$ \\
\hline 1000 & $0.0461 \pm 0.014, \mathrm{t}(269)=-8.7594, \mathrm{p}<0.0001 ; \omega^{2}=0.0126$ \\
\hline 1100 & $0.0384 \pm 0.0147, \mathrm{t}(269)=-6.98, \mathrm{p}<0.0001 ; \omega^{2}=0.0016$ \\
\hline 1200 & $0.0448 \pm 0.0146, \mathrm{t}(269)=-8.1937, \mathrm{p}<0.0001 ; \omega^{2}=-0.002$ \\
\hline 1300 & $0.0631 \pm 0.0154, \mathrm{t}(269)=-10.8933, \mathrm{p}<0.0001 ; \omega^{2}=-0.0074$ \\
\hline 1400 & $0.1071 \pm 0.0184, \mathrm{t}(269)=-15.5377, \mathrm{p}<0.0001 ; \omega^{2}=0.066$ \\
\hline 1500 & $0.1502 \pm 0.0205, \mathrm{t}(269)=-19.5323, \mathrm{p}<0.0001 ; \omega^{2}=0.1728$ \\
\hline 1600 & $0.1909 \pm 0.0257, \mathrm{t}(269)=-19.8154, \mathrm{p}<0.0001 ; \omega^{2}=0.1969$ \\
\hline 1700 & $0.2037 \pm 0.0268, \mathrm{t}(269)=-20.2351, \mathrm{p}<0.0001 ; \omega^{2}=0.2055$ \\
\hline 1800 & $0.1787 \pm 0.0246, \mathrm{t}(269)=-19.3425, \mathrm{p}<0.0001 ; \omega^{2}=0.1967$ \\
\hline 1900 & $0.143 \pm 0.0213, \mathrm{t}(269)=-17.8667, \mathrm{p}<0.0001 ; \omega^{2}=0.1$ \\
\hline 2000 & $0.1168 \pm 0.0221, \mathrm{t}(269)=-14.0688, \mathrm{p}<0.0001 ; \omega^{2}=0.0719$ \\
\hline 2100 & $0.0953 \pm 0.0201, \mathrm{t}(269)=-12.643, \mathrm{p}<0.0001 ; \omega^{2}=0.0656$ \\
\hline
\end{tabular}


bioRxiv preprint doi: https://doi.org/10.1101/2022.02.01.478165; this version posted February 2, 2022. The copyright holder for this preprint (which was not certified by peer review) is the author/funder, who has granted bioRxiv a license to display the preprint in perpetuity. It is made

\begin{tabular}{|c|c|}
\hline Table 3: continued & \\
\hline \multicolumn{2}{|l|}{$\beta(13-19 H z)$} \\
\hline-200 & $0.0067 \pm 0.0391, \mathrm{t}(191)=-0.38236, \mathrm{p}=0.7026 ; \omega^{2}=0.0131$ \\
\hline-100 & $-0.0061 \pm 0.0221, \mathrm{t}(192)=0.62171, \mathrm{p}=0.5349 ; \omega^{2}=0.0147$ \\
\hline 0 & $0.0122 \pm 0.0201, \mathrm{t}(192)=-1.3742, \mathrm{p}=0.171 ; \omega^{2}=-0.0003$ \\
\hline 100 & $0.0323 \pm 0.0132, \mathrm{t}(192)=-5.5143, \mathrm{p}<0.0001 ; \omega^{2}=0.011$ \\
\hline 200 & $0.0125 \pm 0.0114, \mathrm{t}(192)=-2.4815, \mathrm{p}=0.0139 ; \omega^{2}=0.0265$ \\
\hline 300 & $-0.0354 \pm 0.0132, \mathrm{t}(192)=6.0399, \mathrm{p}<0.0001 ; \omega^{2}=0.058$ \\
\hline 400 & $-0.0225 \pm 0.0161, \mathrm{t}(192)=3.1334, \mathrm{p}=0.002 ; \omega^{2}=0.0217$ \\
\hline 500 & $-0.0262 \pm 0.018, \mathrm{t}(192)=3.2814, \mathrm{p}=0.0012 ; \omega^{2}=0.0202$ \\
\hline 600 & $-0.0175 \pm 0.0177, \mathrm{t}(192)=2.2277, \mathrm{p}=0.0271 ; \omega^{2}=0.0164$ \\
\hline 700 & $-0.0089 \pm 0.0167, \mathrm{t}(192)=1.2002, \mathrm{p}=0.2315 ; \omega^{2}=0.0154$ \\
\hline 800 & $0.0059 \pm 0.0145, \mathrm{t}(192)=-0.91096, \mathrm{p}=0.3635 ; \omega^{2}=0.0232$ \\
\hline 900 & $0.0236 \pm 0.0133, \mathrm{t}(192)=-4.0074, \mathrm{p}<0.0001 ; \omega^{2}=0.0184$ \\
\hline 1000 & $0.0002 \pm 0.0117, \mathrm{t}(192)=-0.033248, \mathrm{p}=0.9735 ; \omega^{2}=0.0044$ \\
\hline 1100 & $0.0061 \pm 0.0123, \mathrm{t}(192)=-1.1262, \mathrm{p}=0.2615 ; \omega^{2}=0.0042$ \\
\hline 1200 & $0.0212 \pm 0.0113, \mathrm{t}(192)=-4.2481, \mathrm{p}<0.0001 ; \omega^{2}=0.0007$ \\
\hline 1300 & $0.0403 \pm 0.0118, \mathrm{t}(192)=-7.7319, \mathrm{p}<0.0001 ; \omega^{2}=0.0044$ \\
\hline 1400 & $0.0721 \pm 0.0154, \mathrm{t}(192)=-10.5736, \mathrm{p}<0.0001 ; \omega^{2}=0.0368$ \\
\hline 1500 & $0.0977 \pm 0.0156, \mathrm{t}(192)=-14.1347, \mathrm{p}<0.0001 ; \omega^{2}=0.0725$ \\
\hline 1600 & $0.1319 \pm 0.0162, \mathrm{t}(192)=-18.3303, \mathrm{p}<0.0001 ; \omega^{2}=0.118$ \\
\hline 1700 & $0.1321 \pm 0.0181, \mathrm{t}(192)=-16.4302, \mathrm{p}<0.0001 ; \omega^{2}=0.0797$ \\
\hline 1800 & $0.1126 \pm 0.0154, \mathrm{t}(192)=-16.4416, \mathrm{p}<0.0001 ; \omega^{2}=0.0787$ \\
\hline 1900 & $0.0988 \pm 0.0143, \mathrm{t}(192)=-15.5418, \mathrm{p}<0.0001 ; \omega^{2}=0.0513$ \\
\hline 2000 & $0.1023 \pm 0.0147, \mathrm{t}(192)=-15.7297, \mathrm{p}<0.0001 ; \omega^{2}=0.085$ \\
\hline 2100 & $0.0714 \pm 0.0176, \mathrm{t}(192)=-9.1154, \mathrm{p}<0.0001 ; \omega^{2}=0.0485$ \\
\hline \multicolumn{2}{|l|}{$\gamma(33-48 H z)$} \\
\hline-200 & $0.0284 \pm 0.0424, \mathrm{t}(248)=-1.7162, \mathrm{p}=0.0874 ; \omega^{2}=0.0084$ \\
\hline-100 & $-0.0237 \pm 0.0183, \mathrm{t}(248)=3.3185, \mathrm{p}=0.001 ; \omega^{2}=0.016$ \\
\hline 0 & $-0.0176 \pm 0.0374, \mathrm{t}(248)=1.2047, \mathrm{p}=0.2295 ; \omega^{2}=0.0062$ \\
\hline 100 & $0.0117 \pm 0.0086, \mathrm{t}(248)=-3.4988, \mathrm{p}=0.0006 ; \omega^{2}=0.0313$ \\
\hline 200 & $-0.0451 \pm 0.0082, \mathrm{t}(248)=14.0087, \mathrm{p}<0.0001 ; \omega^{2}=0.0592$ \\
\hline 300 & $-0.0514 \pm 0.0107, \mathrm{t}(248)=12.297, \mathrm{p}<0.0001 ; \omega^{2}=0.0485$ \\
\hline 400 & $-0.0414 \pm 0.0138, \mathrm{t}(248)=7.6807, \mathrm{p}<0.0001 ; \omega^{2}=0.0244$ \\
\hline 500 & $-0.0527 \pm 0.0139, \mathrm{t}(248)=9.7, \mathrm{p}<0.0001 ; \omega^{2}=0.0453$ \\
\hline 600 & $-0.0471 \pm 0.0095, \mathrm{t}(248)=12.7011, \mathrm{p}<0.0001 ; \omega^{2}=0.0838$ \\
\hline 700 & $-0.0497 \pm 0.0083, \mathrm{t}(248)=15.2964, \mathrm{p}<0.0001 ; \omega^{2}=0.0716$ \\
\hline 800 & $-0.0306 \pm 0.0076, \mathrm{t}(248)=10.2899, \mathrm{p}<0.0001 ; \omega^{2}=0.0584$ \\
\hline 900 & $-0.0015 \pm 0.0076, \mathrm{t}(248)=0.51818, \mathrm{p}=0.6048 ; \omega^{2}=0.0098$ \\
\hline 1000 & $-0.0053 \pm 0.0084, \mathrm{t}(248)=1.6083, \mathrm{p}=0.109 ; \omega^{2}=0.0387$ \\
\hline 1100 & $-0.0153 \pm 0.0086, \mathrm{t}(248)=4.578, \mathrm{p}<0.0001 ; \omega^{2}=0.0262$ \\
\hline 1200 & $-0.0184 \pm 0.0074, \mathrm{t}(248)=6.3718, \mathrm{p}<0.0001 ; \omega^{2}=0.0044$ \\
\hline 1300 & $-0.0282 \pm 0.0092, \mathrm{t}(248)=7.8115, \mathrm{p}<0.0001 ; \omega^{2}=0.0172$ \\
\hline 1400 & $-0.0379 \pm 0.0102, \mathrm{t}(248)=9.54, \mathrm{p}<0.0001 ; \omega^{2}=-0.0012$ \\
\hline 1500 & $-0.027 \pm 0.01, \mathrm{t}(248)=6.9461, \mathrm{p}<0.0001 ; \omega^{2}=0.0096$ \\
\hline 1600 & $-0.0199 \pm 0.0099, \mathrm{t}(248)=5.1705, \mathrm{p}<0.0001 ; \omega^{2}=0.0152$ \\
\hline 1700 & $0.0107 \pm 0.0101, \mathrm{t}(248)=-2.6985, \mathrm{p}=0.0074 ; \omega^{2}=0.0446$ \\
\hline 1800 & $0.0187 \pm 0.0107, \mathrm{t}(248)=-4.452, \mathrm{p}<0.0001 ; \omega^{2}=0.0499$ \\
\hline 1900 & $0.0722 \pm 0.0101, \mathrm{t}(248)=-18.2718, \mathrm{p}<0.0001 ; \omega^{2}=0.0711$ \\
\hline 2000 & $0.089 \pm 0.0108, \mathrm{t}(248)=-21.1006, \mathrm{p}<0.0001 ; \omega^{2}=0.0799$ \\
\hline 2100 & $0.0786 \pm 0.0106, \mathrm{t}(248)=-18.974, \mathrm{p}<0.0001 ; \omega^{2}=0.0525$ \\
\hline
\end{tabular}


bioRxiv preprint doi: https://doi.org/10.1101/2022.02.01.478165; this version posted February 2, 2022. The copyright holder for this preprint (which was not certified by peer review) is the author/funder, who has granted bioRxiv a license to display the preprint in perpetuity. It is made

\begin{tabular}{|l|l|} 
Table 3: continued & available under aCC-BY 4.0 International license. \\
\hline$\Gamma(83-98 H z)$ & \\
\hline-200 & $0.0176 \pm 0.0364, \mathrm{t}(229)=-1.1913, \mathrm{p}=0.2348 ; \omega^{2}=0.0056$ \\
-100 & $-0.0091 \pm 0.0275, \mathrm{t}(233)=0.82159, \mathrm{p}=0.4121 ; \omega^{2}=0.0148$ \\
0 & $-0.0183 \pm 0.0211, \mathrm{t}(230)=2.1443, \mathrm{p}=0.0331 ; \omega^{2}=0.0103$ \\
100 & $-0.0491 \pm 0.0057, \mathrm{t}(233)=21.2992, \mathrm{p}<0.0001 ; \omega^{2}=0.0797$ \\
200 & $-0.0532 \pm 0.0067, \mathrm{t}(233)=19.596, \mathrm{p}<0.0001 ; \omega^{2}=0.0842$ \\
300 & $-0.002 \pm 0.0071, \mathrm{t}(233)=0.68699, \mathrm{p}=0.4928 ; \omega^{2}=0.0389$ \\
400 & $-0.0159 \pm 0.0073, \mathrm{t}(233)=5.3819, \mathrm{p}<0.0001 ; \omega^{2}=0.029$ \\
500 & $-0.0288 \pm 0.008, \mathrm{t}(233)=8.8849, \mathrm{p}<0.0001 ; \omega^{2}=0.0434$ \\
600 & $-0.0059 \pm 0.0096, \mathrm{t}(233)=1.536, \mathrm{p}=0.1259 ; \omega^{2}=0.0284$ \\
700 & $-0.0118 \pm 0.0076, \mathrm{t}(233)=3.8498, \mathrm{p}=0.0002 ; \omega^{2}=0.0319$ \\
800 & $-0.0049 \pm 0.0083, \mathrm{t}(233)=1.4611, \mathrm{p}=0.1453 ; \omega^{2}=0.0272$ \\
900 & $-0.0127 \pm 0.0066, \mathrm{t}(233)=4.8156, \mathrm{p}<0.0001 ; \omega^{2}=0.0282$ \\
1000 & $0.0011 \pm 0.0088, \mathrm{t}(233)=-0.30018, \mathrm{p}=0.7643 ; \omega^{2}=0.0133$ \\
1100 & $0.0005 \pm 0.0081, \mathrm{t}(233)=-0.14972, \mathrm{p}=0.8811 ; \omega^{2}=0.0093$ \\
1200 & $-0.0111 \pm 0.0063, \mathrm{t}(233)=4.3941, \mathrm{p}<0.0001 ; \omega^{2}=0.0099$ \\
1300 & $-0.0048 \pm 0.0057, \mathrm{t}(233)=2.0878, \mathrm{p}=0.0379 ; \omega^{2}=0.0051$ \\
1400 & $-0.0146 \pm 0.007, \mathrm{t}(233)=5.1816, \mathrm{p}<0.0001 ; \omega^{2}=0.0011$ \\
1500 & $-0.0259 \pm 0.0071, \mathrm{t}(233)=9.0215, \mathrm{p}<0.0001 ; \omega^{2}=-0.0062$ \\
1600 & $-0.0367 \pm 0.0077, \mathrm{t}(233)=11.8365, \mathrm{p}<0.0001 ; \omega^{2}=-0.0103$ \\
1700 & $-0.0302 \pm 0.007, \mathrm{t}(233)=10.7248, \mathrm{p}<0.0001 ; \omega^{2}=-0.0225$ \\
1900 & $-0.0325 \pm 0.0068, \mathrm{t}(233)=11.9615, \mathrm{p}<0.0001 ; \omega^{2}=0.0216$ \\
2000 & $-0.0206 \pm 0.006, \mathrm{t}(233)=8.4922, \mathrm{p}<0.0001 ; \omega^{2}=0.0336$ \\
2100 & $-0.0418 \pm 0.0097, \mathrm{t}(233)=10.6327, \mathrm{p}<0.0001 ; \omega^{2}=0.0104$ \\
\hline
\end{tabular}


bioRxiv preprint doi: https://doi.org/10.1101/2022.02.01.478165; this version posted February 2, 2022. The copyright holder for this preprint (which was not certified by peer review) is the author/funder, who has granted bioRxiv a license to display the preprint in perpetuity. It is made avaitate under a

\begin{tabular}{|l|l|l|l|l|}
\hline & \multicolumn{4}{|c|}{ maximum mean burst rate } \\
\hline frequency band & load 0 & load 1 & load 2 & load 3 \\
\hline$\alpha(8-12 \mathrm{~Hz})$ & $0.0287 \pm 0.0009$ & $0.0236 \pm 0.0004$ & $0.0208 \pm 0.0003$ & $0.0241 \pm 0.0004$ \\
& at $677 \mathrm{~ms}$ & at $1272 \mathrm{~ms}$ & at $1278 \mathrm{~ms}$ & at $1264 \mathrm{~ms}$ \\
$\beta(13-19 \mathrm{~Hz})$ & $0.0675 \pm 0.0011$ & $0.0787 \pm 0.0007$ & $0.0732 \pm 0.0018$ & $0.0755 \pm 0.0007$ \\
& at $571 \mathrm{~ms}$ & at $1255 \mathrm{~ms}$ & at $1249 \mathrm{~ms}$ & at $1259 \mathrm{~ms}$ \\
$\gamma(33-48 \mathrm{~Hz})$ & $0.0687 \pm 0.0007$ & $0.0834 \pm 0.0008$ & $0.0759 \pm 0.0019$ & $0.0757 \pm 0.0017$ \\
& at $52 \mathrm{~ms}$ & at $620 \mathrm{~ms}$ & at $577 \mathrm{~ms}$ & at $641 \mathrm{~ms}$ \\
$\Gamma(83-98 \mathrm{~Hz})$ & $0.0903 \pm 0.0028$ & $0.086 \pm 0.0012$ at & $0.0796 \pm 0.002$ at & $0.0768 \pm 0.0013$ \\
& at $349 \mathrm{~ms}$ & $251 \mathrm{~ms}$ & $533 \mathrm{~ms}$ & at $478 \mathrm{~ms}$ \\
\hline
\end{tabular}


bioRxiv preprint doi: https://doi.org/10.1101/2022.02.01.478165; this version posted February 2, 2022. The copyright holder for this preprint (which was not certified by peer review) is the author/funder, who has granted bioRxiv a license to display the preprint in perpetuity. It is made

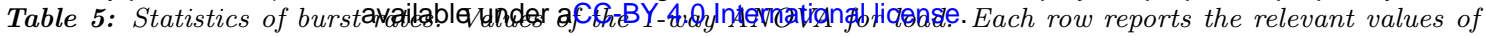
the significant phases indicated in Fig. 4 A and SFig. 4., ordered chronologically.

\begin{tabular}{|l|l|}
\hline$\alpha(8-12 H z)$ & $\gamma(33-48 H z)$ \\
\hline$F_{(2,2)} \geq 3.039, p \leq 0.0485, \omega^{2} \geq 0.0054$ & $F_{(2,2)} \geq 3.0986, p \leq 0.0457, \omega^{2} \geq 0.0056$ \\
& $F_{(2,2)} \geq 3.207, p \leq 0.041, \omega^{2} \geq 0.0059$ \\
\hline$\beta(13-19 H z)$ & $\Gamma(83-98 H z)$ \\
\hline$F_{(2,2)} \geq 3.0707, p \leq 0.047, \omega^{2} \geq 0.0055$ & $F_{(2,2)} \geq 3.0345, p \leq 0.0487, \omega^{2} \geq 0.0054$ \\
$F_{(2,2)} \geq 3.4829, p \leq 0.0312, \omega^{2} \geq 0.0066$ & $F_{(2,2)} \geq 3.6008, p \leq 0.0278, \omega^{2} \geq 0.0069$ \\
$F_{(2,2)} \geq 3.0093, p \leq 0.0499, \omega^{2} \geq 0.0054$ & $F_{(2,2)} \geq 3.0612, p \leq 0.0474, \omega^{2} \geq 0.0055$ \\
$F_{(2,2)} \geq 3.2254, p \leq 0.0403, \omega^{2} \geq 0.0059$ & $F_{(2,2)} \geq 3.0263, p \leq 0.0491, \omega^{2} \geq 0.0054$ \\
$F_{(2,2)} \geq 3.1102, p \leq 0.0452, \omega^{2} \geq 0.0056$ & $F_{(2,2)} \geq 3.1971, p \leq 0.0414, \omega^{2} \geq 0.0058$ \\
$F_{(2,2)} \geq 3.1779, p \leq 0.0422, \omega^{2} \geq 0.0058$ & $F_{(2,2)} \geq 3.2945, p \leq 0.0376, \omega^{2} \geq 0.0061$ \\
$F_{(2,2)} \geq 3.076, p \leq 0.0467, \omega^{2} \geq 0.0055$ & $F_{(2,2)} \geq 3.3135, p \leq 0.0369, \omega^{2} \geq 0.0062$ \\
& $F_{(2,2)} \geq 3.6533, p \leq 0.0264, \omega^{2} \geq 0.0071$ \\
& $F_{(2,2)} \geq 3.6822, p \leq 0.0256, \omega^{2} \geq 0.0071$ \\
& $F_{(2,2)} \geq 3.8703, p \leq 0.0213, \omega^{2} \geq 0.0076$ \\
& $F_{(2,2)} \geq 3.0757, p \leq 0.0467, \omega^{2} \geq 0.0055$ \\
& $F_{(2,2)} \geq 3.0663, p \leq 0.0472, \omega^{2} \geq 0.0055$ \\
& $F_{(2,2)} \geq 3.9306, p \leq 0.02, \omega^{2} \geq 0.0078$ \\
& $F_{(2,2)} \geq 3.4978, p \leq 0.0308, \omega^{2} \geq 0.0066$ \\
\hline
\end{tabular}

